OPEN ACCESS

Edited by: Emanuela Ricciotti, University of Pennsylvania, United States

Reviewed by: Lihong Chen,

Dalian Medical University, China Carlo Riccardi, University of Perugia, Italy

*Correspondence: Juriyati Jali juriyatijali@ukm.edu.my

Specialty section: This article was submitted to Inflammation Pharmacology, a section of the journal

Frontiers in Pharmacology

Received: 09 July 2018 Accepted: 08 August 2018 Published: 07 September 2018

Citation:

Attiq A, Jalil J, Husain K and Ahmad W (2018) Raging the War Against Inflammation With Natural Products. Front. Pharmacol. 9:976. doi: 10.3389/fphar.2018.00976

\section{Raging the War Against Inflammation With Natural Products}

\author{
Ali Attiq ${ }^{1}$, Juriyati Jalii ${ }^{1 *}$, Khairana Husain ${ }^{1}$ and Waqas Ahmad ${ }^{2}$ \\ ${ }^{1}$ Drug and Herbal Research Centre, Faculty of Pharmacy, University Kebangsaan Malaysia, Kuala Lumpur, Malaysia, ${ }^{2}$ School \\ of Pharmaceutical Sciences, Universiti Sains Malaysia, Gelugor, Malaysia
}

Over the last few decade Non-Steroidal Anti-Inflammatory Drugs (NSAIDs) are the drugs of choice for treating numerous inflammatory diseases including rheumatoid arthritis. The NSAIDs produces anti-inflammatory activity via inhibiting cyclooxygenase enzyme, responsible for the conversation of arachidonic acid to prostaglandins. Likewise, cyclooxegenase-2 inhibitors (COX-2) selectively inhibit the COX-2 enzyme and produces significant anti-inflammatory, analgesic, and anti-pyretic activity without producing COX-1 associated gastrointestinal and renal side effects. In last two decades numerous selective COX-2 inhibitors (COXIBs) have been developed and approved for various inflammatory conditions. However, data from clinical trials have suggested that the prolong use of COX-2 inhibitors are also associated with life threatening cardiovascular side effects including ischemic heart failure and myocardial infection. In these scenario secondary metabolites from natural product offers a great hope for the development of novel anti-inflammatory compounds. Although majority of the natural product based compounds exhibit more selectively toward COX-1. However, the data suggest that slight structural modification can be helpful in developing COX-2 selective secondary metabolites with comparative efficacy and limited side effects. This review is an effort to highlight the secondary metabolites from terrestrial and marine source with significant COX-2 and COX-2 mediated PGE 2 inhibitory activity, since it is anticipated that isolates with ability to inhibit COX-2 mediated $\mathrm{PGE}_{2}$ production would be useful in suppressing the inflammation and its classical sign and symptoms. Moreover, this review has highlighted the potential lead compounds including berberine, kaurenoic acid, $\alpha$-cyperone, curcumin, and zedoarondiol for further development with the help of structure-activity relationship (SAR) studies and their current status.

Keywords: cyclooxygenase-2, inflammation, natural products, prostaglandin $E_{2}$, cyclooxygenase pathway, antiinflammatory

\section{INTRODUCTION}

Inflammation is a tightly regulated immune-protective response to combat xenobiotic invasion, mechanical, chemical, and thermal injury (Nathan, 2002; Barton, 2008). The initiation and the maintenance of the inflammation is carried out by pro-inflammatory mediators whose activity balanced out by the anti-inflammatory mediators responsible for the limiting the inflammation, once the instigating factor is removed (Segal et al., 2000; Nathan, 2002). However, there are several factors including stress (Han et al., 2002), chromosomal aberration (Shacter and Weitzman, 2002), and environmental factors (Shishodia et al., 2003) that can disturb this balance and lead to excessive 
production of prostaglandin $\mathrm{E}_{2}$, via up-regulating the COX2 activity, which consequently leads to inflammatory mediated diseases including cancer (Pockaj et al., 2004; Misra et al., 2018), Alzheimer's diseases (Faden et al., 2016), and acute renal failure (Gomez et al., 2014; Tucker et al., 2015). NSAIDs are the drugs of choice to suppress the COX-2 associated $\mathrm{PGE}_{2}$ production (Ullah et al., 2016). However, the prolong use of NSAIDs has been associated with serious and sometimes life threatening side effects (Bjarnason and Rainsford, 2001; Mattia and Coluzzi, 2005). Hence it is imperative to find out alternative therapeutic regimen with comparative efficacy but with fewer side effects.

The natural products with medicinal properties have been used to treat all sorts of inflammatory conditions (Petrovska, 2012; Daniel, 2016). These traditional anti-inflammatory remedies later become the counter stones for the production of Aspirin, the first natural product derived synthetic antiinflammatory drug (Attiq et al., 2017). Since then the exploration of natural bioactive compounds has been quite promising, resulting in the discovery of numinous secondary metabolites with extra ordinary bioactivities including artemisinin (Dewick, 2002), vinblastine (Cragg et al., 1997), pilocarpine etc (Patwardhan et al., 2004; Zhang L. et al., 2005). In the light of the fact, that natural products have advantageous structural diversity over synthetic compounds, makes them a potential source of novel compounds with potent anti-inflammatory activity (Tulp and Bohlin, 2002; Grabowski et al., 2008; Harvey, 2008). Henceforth this review is an effort to highlight the secondary metabolites form plant, fungi, marine and terrestrial algae source with significant COX-2 activity. Moreover, the compounds with additional $\mathrm{PGE}_{2}$ inhibitory activity were also included in this review, since isolates with potential to inhibit COX-2 mediated $\mathrm{PGE}_{2}$ production are expected to exhibit significant anti-inflammatory, antipyretic, and analgesic activity.

\section{CYCLOOXYGENASE PATHWAY}

The arachadonic acid (AA) is the most essential metabolic precursor for numerous inflammatory pathways (Zeldin, 2001). It is a 20 carbon unsaturated fatty acid, widely distributed in lipid bilayer membrane in a resting position (Sevanian and Kim, 1985). However, it has been reported that numerous external and internal factor have the tenacity to activate the phospholipase $\mathrm{A}_{2}\left(\mathrm{PLA}_{2}\right)$. This activation cleaves the membrane bound AA from the phospholipids and makes it available for three major inflammatory pathways including cytochrome P-450 monooxygenase (Capdevila et al., 2000; De Montellano, 2005), lipoxygenase (Piomelli et al., 1987), and cyclooxygenase pathway (Kuehl and Egan, 1980; Santos et al., 2017).

The major scope of this current review is Cyclooxygenase pathway, which is considered as one of the most comprehensively studied inflammatory pathway in mammals (Shih et al., 2015). The pathway begins with the conversation of AA to $\mathrm{PGH}_{2}$, major metabolic substrate for the prostaglandin and thromboxane associated synthases (Sugimoto et al., 2015). This conversation take place due to the action of proton donor oxygen oxidoreductase (prostaglandin $\mathrm{G} / \mathrm{H}$ synthase) commonly referred as cyclooxygenases. The whole process is carried out in two phases. In first phase, prostaglandin $\mathrm{G}_{2}$ (PGG2) production is carried out through oxidation of AA, which results in addition of two oxygen molecules to the AA structure (Van der Donk et al., 2002; Rouzer and Marnett, 2003). In second phase, $\mathrm{PGG}_{2}$ bind to the $\mathrm{PGG}_{2}$ specific reactive site, where the reduction of $\mathrm{PGG}_{2}$ take place through lipid peroxidation, which results in the production of $\mathrm{PGH}_{2}$ (Kawahara et al., 2015).

\section{MECHANISM OF ACTION OF CYCLOOXYGENASE PATHWAY}

The cyclooxygenase pathway initiates with the formation of hydroperoxy endoperoxide $\left(\mathrm{PGG}_{2}\right.$.) from AA (Samuelsson et al., 1978). This rate-limiting step is carried out on Carbon-13 of AA, where the abstraction of pro-S hydrogen takes place (Schneider and Brash, 2000). The activity of peroxidase is significantly important in activating and consequently making cyclooxygenase enzyme available for the reaction. Peroxide substrate undergoes two-electron reduction leading to ferric heme oxidation, which is responsible for the formation of Tyr385, oxo-ferryl porphyrin radical-cation (Van der Donk et al., 2002). Tyr-385 reduces the heme through electron transfer and facilitates the formation of tyrosine radical at the active site of cyclooxygenase (Chandrasekharan and Simmons, 2004). This residue is important for the abstraction of pro-S hydrogen from AA which serve as a initiation signal for the cyclooxygenase reaction (Kawahara et al., 2015). In addition, the formation of $\mathrm{PGG}_{2}$ takes place through the reduction of peroxyl radical to the hydroperoxide (Van der Donk et al., 2002). Once activated, COX can undergo several turn over without any prior activation. Moreover, the reaction proceed with the reduction of 15hydroperoxy of $\mathrm{PGG}_{2}$ to $\mathrm{PGH}_{2}$ (Van der Donk et al., 2002; Kawahara et al., 2015). For further clarification mechanism of action of cyclooxygenase pathway is simplified in Figure 1.

\section{COX-1 AND COX-2 STRUCTURAL AND FUNCTIONAL COMPARISON}

The cyclooxygenase enzymes can be further classified into two distinctive iso-enzymes, COX-1 and COX-2 (Fitzpatrick, 2004; Mbonye et al., 2008). COX-1 is constitutive in nature and widely expressed on various parts of the body including platelets (Crofford, 1997), kidney (Soslow et al., 2000), gastric mucosal lining (Jackson et al., 2000), duodenum (Crofford, 1997), jejunum (Crofford, 1997), and lungs (Smith et al., 2000; Chandrasekharan and Simmons, 2004). COX-1 plays significant role in carrying out numerous physiological function including platelet aggregation (Morita, 2002), hemostasis (Crofford, 1997), and protection of gastric mucosa (Brzozowski et al., 2001) and hence COX1 is also commonly referred as "house keeping enzyme." On the contrary, COX-2 cDNA was cloned from phorbol ester induced 3T3 fibroblasts. This discovery was a milestone in characterizing the structural and functional comparison of COX isoenzymes (Fitzpatrick, 2004). Despite its structural similarity with COX-1, enzymatic activity pattern of COX-2 is quite 


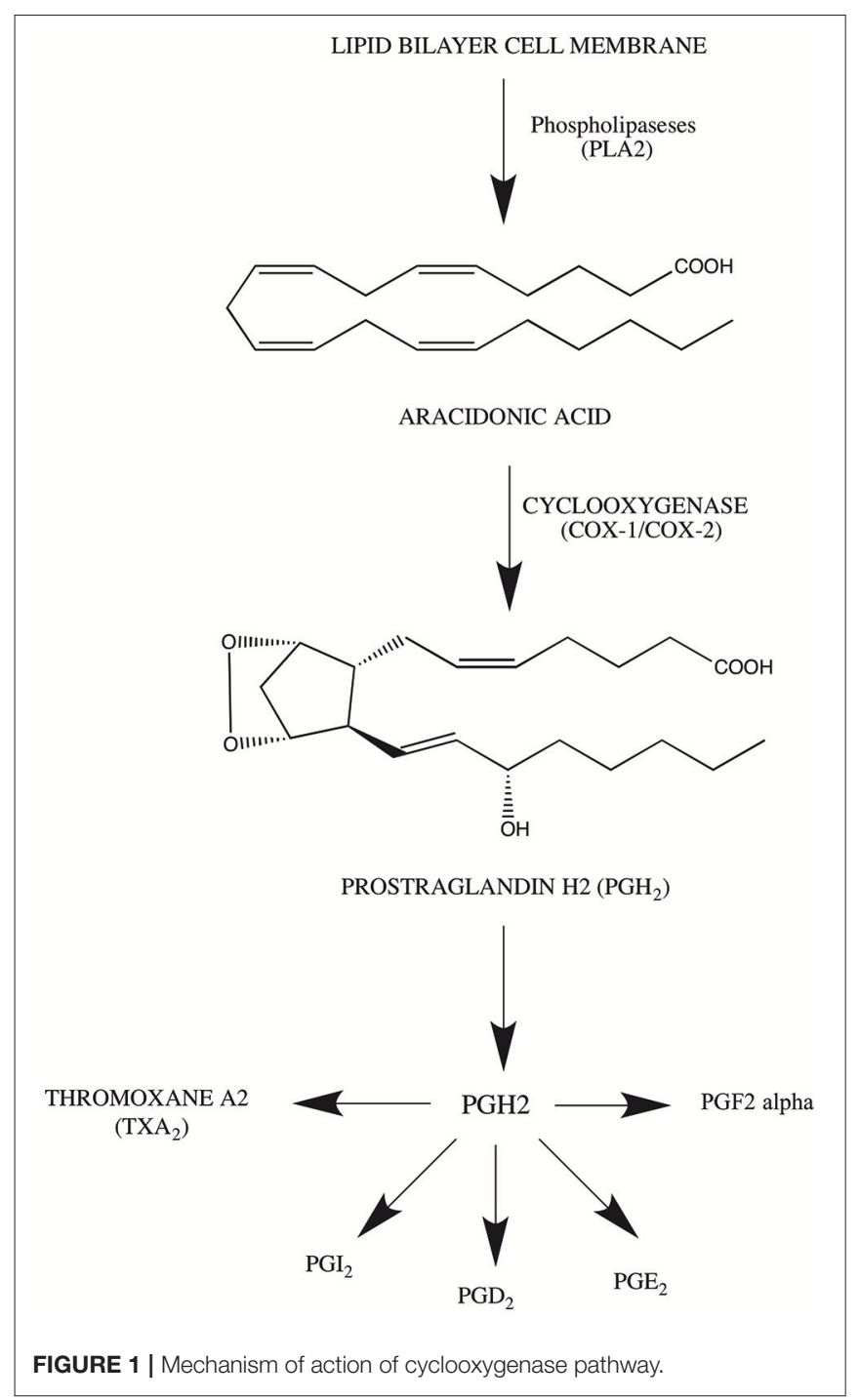

different due to Ptgs-2 gene. The turn over of COX-2 mRNA is relatively quicker then COX-1 mRNA due to the presence of $3^{\prime}$-untranslated instability sequences (Van der Donk et al., 2002; Rouzer and Marnett, 2003). Due to which COX-2 can be easily induced by various endogenous and exogenous stimulus including pro inflammatory cytokines (IL-1 and IL-6) (Samad et al., 2001), tumor necrosis factor $\alpha$ (TNF- $\alpha$ ) (Wang and Smart, 1999), lipopolysaccharide (LPS) (Eliopoulos et al., 2002), and stress (Han et al., 2002; Ponik and Pavalko, 2004). Once induced COX-2 can cause excessive production of $\mathrm{PGE}_{2}$ (major metabolic product of COX-2) along with other prostaglandin which lower the pain threshold and induce pain, sensitize the nerve ending, increase vascular permeability and hence paving the path for inflammatory associated diseases (Mbonye et al., 2008).

The COX-1 and COX-2 consist of 576 and 581 amino acids, while both iso-enzymes share the same molecular mass of $70 \mathrm{kDa} /$ monomer, along with their primary and tertiary structure (Rouzer and Marnett, 2009). Both iso-enzymes have three mannose oligosaccharides, which plays significant role in protein folding, which is responsible for imparting functional conformation to both iso-enzymes. Moreover, there is a forthadditional oligosaccharide specifically expressed on COX-2 that is responsible for the degradation and termination of its enzymatic activity. (Chandrasekharan and Simmons, 2004; Rouzer and Marnett, 2009). Structural similarly of both isoenzymes can be judged form the fact that it has been observed that the 3D structures of both isoenzymes are almost superimposable. There are three domains present on individual subunits of dimers out of which the bulkiest one with $>117$ resides serve as the catalytic domain, which make up the active site for cyclooxygenase and peroxidase (Kurumbail et al., 2001; Mbonye et al., 2008). While the membrane-biding domain, which exhibit peroxidase specific active site are present on the distal part of the protein, which consist of heam group attached at the base of the cleft (Kurumbail et al., 2001). Except for the hydrophobic amino acid cluster, which makes up the dome over the cleft and repels the attachment, the rest of the structure offers high accessibility of solvent to the heam group. This structural configuration of the active site explains the COX-2 peroxidase substrate structural specificity, which limits the binding of numerous primary and secondary biosynthetic hydroperoxidase (Smith et al., 2000). Cyclooxygenase active site is present on the exterior distal part of protein which is adjacent to the L-shaped channel of the membrane-binding domain (Smith et al., 2000; Rouzer and Marnett, 2009). A specific amino acid sequence is attached at the opening of the channel. This sequence acts as a barrier, which allows the substrate and antagonist to attach with active site. Once the barrier is removed cyclooxygenase site is available for the AA binding (Rouzer and Marnett, 2009). The proceeding reaction is carried out in two phases, in phase one carboxylic group attach at the constriction, while in second phase $\omega$-methyl gets attach to the channel terminus. Once these two attachment phases are complete, AA bends it carbon-13 into the channel allowing the attachment with Tyr-385 which initiates the cyclooxygenase reaction (Smith et al., 2000; Garavito et al., 2002).

\section{ROLE OF CYCLOOXYGENASE IN INFLAMMATION}

COX-1 is often referred as "house keeping" enzyme due to its constitutive role in human physiology, however recent COX1 knock out mice studies have revealed COX-1 also plays significant role in development and progression of inflammation (Langenbach et al., 1999; Kurumbail et al., 2001; Morita, 2002; Aid et al., 2008). It has been observed that COX1 expression is up-regulated in resident inflammatory cells, responsible for carrying out acute inflammatory response and cell differentiation. In addition it has been observed that both isoenzymes were equally expressed on adjuvant induced arthritis model and similar pattern of distribution was observed in the synovial fluid extracted from rheumatoid arthritis patients from tertiary health care centers (McAdam et al., 2000). It could be inferred from above stated studies that COX-1 associated 
metabolic products are associated with initiation of inflammatory acute phase, while the COX-2 expression is responsible for maintaining the inflammatory response (Schönbeck et al., 1999; McAdam et al., 2000). While the COX-2 deletion or selective inhibition in different animal models have shown ambivalent results. It has been observed that COX-2 deletion or selective inhibition may ameliorate or even worsen the inflammatory response. In few inflammatory models COX-2 deletion has caused worsening of gastric ulcers hence indicating its importance in gastric mucosal protection (Wallace et al., 2000). Likewise, in a recent study conducted to evaluate the pattern of inflammatory response in COX-1- and COX-2 knockout rat models revealed that deletion of both COX isoenzyme can illicit acute phase inflammation. However, both models have shown variable pattern of onset, intensity and duration of inflammation. While in another study it was observed that deletion of COX-1 known gene let to the significant reversal of AA-induced edema, which exhibit significant role in resolving inflammation. Moreover, in the same study similar results were in observed where COX-2 gene deletion led to resolution of AA-induced edema in wild type COX-2 knockout model (Langenbach et al., 1995; Morham et al., 1995). Base on the above stated facts it could be inferred that both iso-enzyme play significant in early and late phase of the inflammatory response depending upon the inflammatory stimulus and degree of expression on that particular tissue (Dinchuk et al., 1995). Similarly in another study it was observed that expressions of both iso-enzyme are equally expressed in synovial fluid isolated patients suffering from synovitis. In the same study, $\mathrm{K} / \mathrm{BxN}$ serum-transfer arthritis model exhibited an early upregulation of COX-1 expression and significant increase in the production of COX-1 derived $\mathrm{PGI}_{2}$, which plays significant role in the development and maintenance of arthritis. While after deletion of the COX-2 in knockout model unexpectedly let to the resolution of synovial inflammation and remodeling of joint destruction (Myers L. K. et al., 2000). Moreover, in another study it was observed that COX-1 and COX-2 deletion led to the significant deceases in $\mathrm{PGE}_{2}$ production and reversal of inflammation in air pouch model. Additionally it was also observed that pretreatment with selective COX-2 inhibitor NS398 (positive control) was able to resolve the inflammation and decreases the concentration of $\mathrm{PGE}_{2}$ in the similar manner (Langenbach et al., 1999). It was concluded from the study that COX-2 deletion have exhibited $75 \%$ fall in prostaglandin production, while COX-1 deletion in wild- type mice only led to $25 \%$ reduction in total prostaglandin production. It can be inferred from the study that both iso-ensyme are involved in prostaglandins production and COX-2 deletion may lead to resolution of acute inflammatory response (Langenbach et al., 1999). Moreover, it has been reported that cyclooxygenase iso-enzymes are likely to reverse their functional activities specifically in brain. Which is based upon an observation that intrathecal LPS administration in COX-1 knock-out mice have ameliorated the inflammatory response, while in COX-2 knock out mice inflammation was exacerbated (Langenbach et al., 1999; Smith and Langenbach, 2001; Ueno et al., 2005; Aid et al., 2008).

\section{PROSTAGLANDIN AND INFLAMMATION}

\section{The Role of Prostaglandins in Mediating Pain and Inflammation}

The $\mathrm{PGE}_{2}$ is responsible for maintaining numerous physiological functions including blood pressure (Armstrong et al., 1976), female reproductive system (Fortier et al., 2008), fertility (Nutting and Cammarata, 1969), protection of gastric mucosa (Lacy and Ito, 1982; Brzozowski et al., 2001), and immune response (Plescia et al., 1975; Phipps et al., 1991). However, in certain pathological conditions the level of $\mathrm{PGE}_{2}$ increases more than 10 fold then the normal concentration, which gives rise to serious complications. For instance, in inflammation elevated level of COX-2 mediated $\mathrm{PGE}_{2}$ production is responsible for exhibiting classical inflammatory sign and symptoms. $\mathrm{PGE}_{2}$ elevates the blood flow toward the inflamed tissue through its vasodilatory activity and increases vascular permeability (Williams and Peck, 1977). Moreover, it induces pain via sensitizing the nerve ending in both central and peripheral nervous system (Mantyh et al., 2002; Kojima et al., 2005). Furthermore, results from recent clinical trials conducted on selective COX-2 inhibitors have stated that classical NSAIDs are equally potent in reducing the $\mathrm{PGE}_{2}$ concentration in both isoforms (Sperling et al., 2001). Hence it can be inferred form the result that COX2 mediated $\mathrm{PGE}_{2}$ production is completely dependent upon the type and site of inflammation. Moreover, recent report suggested that $\mathrm{PGE}_{2}$ level significant dropped after the removal of COX-2 gene form mice arthritic model and averted the overall progress of autoimmune arthritis (Myers $\mathrm{N}$. et al., 2000). In recent study conducted to evaluate the $\mathrm{PGE}_{2}$ role in acute inflammation model suggested pretreatment with $\mathrm{PGE}_{2}$ monoclonal antibody and indomethacin has significant reduced that carrageenan induced edema via suppressing the COX2 mediated $\mathrm{PGE}_{2}$ production (Nakatani et al., 2007). Similar results were observed in rat adjuvant arthritis rat model, where the freund's adjuvant administration leads to excessive $\mathrm{PGE}_{2}$ production and consequent inflammation (Mancini et al., 2001; Nakatani et al., 2007). The infiltration of monocytes and Tlymphocytes represents the inflammatory reaction, which ends up in the paw edema and joint destruction. The results suggests that the up regulation of COX-2 mRNA and COX-2 derived and $\mathrm{PGE}_{2}$ production was observed carrageenan induced paw edema, although no significant change was observed in COX-1 mRNA. While a significant reduction is paw volume was observed upon the administration of COX-2-specific inhibitor SC-58125, which signifies the role of COX-2 in elevated levels of $\mathrm{PGE}_{2}$ responsible for increase in paw volume (Guruprasad et al., 2015). Under the light of above-mentioned studies its evident that COX-2 and COX-2 mediated $\mathrm{PGE}_{2}$ production plays significant role in pain and inflammation.

\section{Microsomal Prostaglandin $E_{2}$ Synthase-1 (PGES-1) and Its Expression}

PGE synthase (PGES) is responsible for the conversation of $\mathrm{PGH}_{2}$ to $\mathrm{PGE}_{2}$. $\mathrm{PGH}_{2}$ is highly unstable and readily gets metabolized by COX-1 and COX-2 (Dannhardt et al., 2000; Tilley et al., 2001). So far three PGES isoforms has been reported to be 
involved in $\mathrm{PGE}_{2}$ production. PGES-1 is a membrane associated synthase and can be induced by various inflammatory mediators, while mPGES-2, and cytosolic cPGES are constitutively expressed intracellularly (Park et al., 2006). cPGES only benefits from the COX-1 activity for $\mathrm{PGH}_{2}$ production, mPGES-2 holds the tenacity to produce $\mathrm{PGH}_{2}$ utilizing both COX-isoforms (Park et al., 2006). While, inducible mPGES-1 is principally benefits form COX-2 for $\mathrm{PGH}_{2}$ production. mPGES-1 is a glutathionedependent enzyme also commonly referenced as microsomal glutathione S-transferasel-like 1 (MGST1-L1) (Ricciotti and FitzGerald, 2011). mPGES-1 share inducible nature with COX2 and both enzymes have shown patterns of synchronized induction upon receiving pro-inflammatory stimulus including TNF- $\alpha$, PAF, IL- $1 \alpha$, and IL-6. The most significant activity of PGES is observed in COX-2 associates delayed $\mathrm{PGE}_{2}$ production phase. In which, pro inflammatory mediator are responsible for inducing the COX-2 dependent mPGES-1 expression (Murakami et al., 2000; Cipollone et al., 2003a). Moreover, pattern of up regulated mPGES-1 activity were also observed with hormonal stimulation, $\beta$-amyloid treatment of astrocytes. Recent studies conducted on TNF- $\alpha$-induced rheumatoid arthritis synovial cells have suggested that pretreatment with dexamethasone successfully down regulated the mPGES-1 mRNA (Murakami et al., 2002). In addition it has been observed that expression of mPGES-1, PGE $_{2}$ catalytic enzyme has seems to be unregulated in LPS-induced rat model with adjuvant arthritis. Which suggested that mPGES-1 expression can be unregulated by pro-inflammatory mediator (Tamura et al., 2016) including LPS and pro-inflammatory cytokines in various parts of the body including gingival fibroblasts, smooth muscle cells, cardiac myocytes, and human endothelial cells (de Crombrugghe et al., 2000; Lundin et al., 2004; Jaulmes et al., 2006). Moreover, the level of mPGES-1 has seemed to be up regulated 10-folds in diabetic patients then the normal healthy individual, suggesting the significant roles of up regulated mPGES-1 expression in development of various pathological conditions (Cipollone et al., 2003b; Sampey et al., 2005; Kosek et al., 2015).

\section{$\mathrm{PGE}_{2}$ (EP) Receptor Physiological Actions and Role in Inflammation}

In past two decades numerous studies have been carried out of knock out mice model to elucidate the physiological functions of EP subtypes in human body. These studies have also been helpful in exploring the specific EP subtypes agonist/antagonist that can be used to innervate, identify and pinpoint the EP sub-types involved in carrying out multifaceted $\mathrm{PGE}_{2}$ pathophysiological actions (Ushikubi et al., 1998). For instance in recent study NSAIDs was successfully able to reduce the pyrogenic fever and release of corticotropin-releasing hormone by blocking the EP1 and EP3 signals transduction to hypothalamus (Matsuoka et al., 2003). Moreover, EP receptors play significant role in regulating the ovulation and fertilization process. In has been observed the expansion of cumulus, which is vital for the ovulation and fertilization, is majorly innervated by EP2 (Hizaki et al., 1999). Additionally, Literature suggests that EP1 and EP2 plays significant role is inducing hyperalgesia during inflammation.
For instance a recent acetic acid writhing test carried out on rat model has suggested the role of EP1 and EP2 in hyperalgesia induced by rapid heat and $\mathrm{pH}$ fluctuations in the body (Hervé et al., 2003). The hypothesis was further cemented by the recent study which stated that $\mathrm{pH}$ and heat induced hyperalgesia was significantly reduced by down regulating the expression of capsaicin receptor TRPV1 mainly innervated by release of $\mathrm{PGE}_{2}$ and $\mathrm{PGI}_{2}$ on EP1 and EP2 receptors (Moriyama et al., 2005). Likewise in the CNS, $\mathrm{PGE}_{2}$ mediated EP2 activation escalated the pain sensation and transmission of nociceptive signals in CNS via glycine-induced tonic inhibition of pain neuron in the dorsal horn (Zeilhofer, 2005). In the light of above stated studies it could be inferred that Prostanoids, particularly $\mathrm{PGE}_{2}$ plays significant role in mediating inflammation. Moreover, it can also be inferred that pro and anti-inflammatory activity of $\mathrm{PGE}_{2}$ are innervated through modulating the EP and IP gene expression on various tissues on the body. For instance recent study suggests that overexpression of EP2 and EP4 has been observed in collagen-induced arthritis rat model, which was also, accompanied by elevated concentration of $\mathrm{PGE}_{2}$ at the site of collagen-induced arthritis (Honda et al., 2006). Likewise in another study test samples from the carrageenaninduced paw edema and carrageenan-induced pleurisy revealed overexpression of EP2, EP3, and IP in exudates (Murata et al., 1997). Moreover, there are several studies, which point out toward the role or EP in the development of inflammation and anaphylactic shocks. A recent study suggests that EP3 receptors are fairly distributed on airway epithelium, which upon activation can result in $\mathrm{PGE}_{2}-\mathrm{EP} 3$ pathway activation eliciting strong anaphylactic allergic inflammation (Murata et al., 1997).

\section{ROLE OF COX-2 AND PGE 2 IN VARIOUS DISEASES}

\section{Autoimmune Diseases}

Several pharmacological studies conducted on eicosanoids have given the genetic evidence of PGs and COX-2, in development of autoimmune diseases including rheumatoid arthritis (RA) (Minghetti, 2004; Lucas et al., 2006). In a recent study conducted on mice arthritis model with knocked out cPLA2, COX-2, mPGES-1 have exhibited significant deceases in inflammatory response in swollen joints. COX-2 mediated intra-articular $\mathrm{PGE}_{2}$ production in inflamed joints is carried out by synoviocytes, which is responsible for progression of RA (Akaogi et al., 2006; Shinkai et al., 2008). Moreover, it has been observed that excessive production of $\mathrm{PGE}_{2}$ can also produce immunosuppressant effects via suppression of IL-2 production by lymphocytes, by indirectly modulating the activation of $\mathrm{CD}^{+}$suppressor cells (Demeure et al., 1997).

\section{Allergic Diseases}

Allergic reactions are significantly mediated by eicosanoids (Rubin and Mollison, 2007). It has been observed that allergic models with knock out cPLA2, 5-LO, COX-2, and CysLT1 have reduced the frequency and intensity of allergic sign and symptoms (Drazen et al., 1999; Harizi et al., 2008). 
During the allergic response eicosanoids are produced by monocytes and T-lymphocytes. These eicosanoids are do not impose their effect of immune system directly rather they are responsible for indirectly modulating the system and producing clinical manifestations associated with allergic reaction which includes blood pressure fluctuation, bronchospasm, diarrhea and fever (Harizi et al., 2008). PGD2, PGE 2 , and PGF2a, IL have no storage space in cells rather they are produced extemporaneously during allergic response. The attachment of allergen with IgE stimulates the $\mathrm{PLA}_{2}$ that results in the production of AA. Which is further metabolized by COX/LOX pathway (Peters et al., 1984; Harizi et al., 2008).

\section{Alzheimer's Disease (AD)}

Formation of Microglial plague, cytokine induced acute phase reaction and activation of complex cascade are the clinical features of Alzheimer's disease. Significant neuronal damage and worsening of sign and symptoms has been observed with inflammation response (Breitner, 1996; Akiyama et al., 2000; $\mathrm{BV}$ and $\mathrm{BE}, 2000)$. A recent study on in vivo rat model of $\mathrm{AD}$ has reported up regulated COX-2 expression and $\mathrm{PGE}_{2}$ level present in cerebrospinal fluid. Moreover, the report suggested that increases COX-2 activity in brain has been associated with the $\mathrm{AD}$ clinical manifestation including amyloidosis and dementia. Hence it is proposed that early treat with NSAIDs or selective COX-2 can ameliorate or even slow down the clinical manifestation of AD (Weggen et al., 2001; Sciulli et al., 2005).

\section{Cancer}

Several pharmacological studies conducted on eicosanoids have highlighted their role in the development and prognoses of numerous cancers (Wang et al., 2004; Krysan et al., 2006). In a recent study conducted in animal model with knock out CPLA2, COX-1, COX-2, and mPGES-1 have exhibited suppression in tumor development, while rat model will knock out PGD synthase resulted in proliferation of tumor cells (Takaku et al., 2000; Tiano et al., 2002; Kawamori et al., 2005). COX-2 and LOX enzymatic activity and their byproduct have proved to be essential for cancer development of numerous cancers. Biopsy form breast cancer, colon cancer, and prostate have exhibited higher levels of mPGES-1 and COX2 overexpression. COX-2 mediated $\mathrm{PGE}_{2}$ provide safe harbor for the cancer development through promoting angiogenesis, stimulating cellular proliferation, angiogenesis, and removing the cell cycle check points (Öhd et al., 2003; Ding et al., 2005; Paruchuri et al., 2006). Immunosuppression is the most common clinical manifestation associated with tumor development (Sharma et al., 2003). Data have suggested that tumor cell weaken the immune-surveillance via producing excessive amount of immunosuppressive mediator (Avis et al., 2001). Herein the $\mathrm{PGE}_{2}$ serve a pseudo-immunosuppressive mediator via obstructing cell differentiation properties of dendritic cell which results is production of uncontrolled undifferentiated cells (Pradono et al., 2002; Edelman et al., 2008).

\section{NATURAL COX-2 AND PGE 2 INHIBITOR PAST, PRESENT AND FUTURE}

The elucidation and isolation of crystal structure COX-2 opened up avenue for new therapeutic options and drug designs (Kiefer et al., 2000; Pouplana et al., 2002). The discovery of COX2 revolutionized the whole anti-inflammatory treatment, since it was the common perception that unwanted side effects of the NSAIDs are due to inhibition of constitutive role of COX1. Hence it was proposed that selective COX-2 inhibitors are expected to produce similar therapeutic activity like classical NSAIDs, but with lesser side effects (Ray et al., 2002). However, Rofecoxib, the first selective COX-2 inhibitor was far from being perfect. Clinical trial results suggested that prolong use of rofecoxib can lead to serious cardiovascular complication including cardiomayopathy and ischemic heart failure through disturbing the hemostatic prostacyclin/thromboxane balance (Bing and Lomnicka, 2002). Moreover, a randomized placebocontrolled trial conducted on roficoxib, to study the role of selective COX-2 in prevention of adenomatous polyps raised serious safely issues. The patient treated with selective COX2 inhibitors exhibited life threatening myocardial infarction symptoms, over the course of 18 months of treatment. This event raise safety concerns for all the members of selective COX2 inhibitors (Dieppe et al., 2004). However, over the course of two decades several new members of this class including celecoxib, parecoxib, valdecoxib, and Lumiracoxib have come into the market, with claimed gastrointestinal benefits and lacking cardiovascular symptoms (FitzGerald, 2004; Lyon, 2004).

The natural products have served the human kind for thousand of years. For centuries, traditional remedies were on the only source medicine for treating various diseases (Raja et al., 2016). Likewise there are evidences from pre historic times, which suggest the use of traditional remedies for all sort of inflammatory condition. These ethno-pharmacological practices can be dated back to $400 \mathrm{BC}$, where Greeks used bark of willow tree as a common medical practice to treat inflamed joints and fever. This traditional remedy led to development of Aspirin, the first synthetic plant derived drug to treat rheumatic diseases (Vane, 1971). This discovery further highlighted the importance of natural products in drug discovery and design. In the light of above facts, natural products offer great hope for the discovery of lead compounds with structural diversity and superior efficacy (Polya, 2003). The current review is an effort to highlight the isolates from plant, animal, fungal, and terrestrial and marine algal species with $\mathrm{COX}-2$ and $\mathrm{PGE}_{2}$ activity. Since COX-2 derived $\mathrm{PGE}_{2}$ production is responsible for progression of numerous inflammatory condition hence it is widely accepted that phytochemical with potent $\mathrm{PGE}_{2}$ and COX2 will exhibit mark analgesic, antipyretic and anti-inflammatory activity.

\section{Alkaloids}

Berberis species are used as traditional medicine for treating various inflammatory diseases. Specifically crude roots and bark extracts are used as household remedy for rheumatism, backache and rheumatic fever (Yeşilada and Küpeli, 2002). 
Numerous studies have suggested the anti-inflammatory activity is due to the abundance of berberine (1) (Figure 2), an alkaloid present inside the Berberis sp. A recent study conducted on rat model to evaluate the anti-inflammatory activity of Berberis vulgaris suggested that berberine (1) has exhibited strong anti-inflammatory activity. However, in same study it was reported that treatment with berberine (1) is also associated with concentration dependent gastric ulceration. Which led to the conclusion that berbarine share its mechanism of actions with classical NSIADs that produce mark anti-inflammatory activity via inhibiting prostaglandin synthesis that may also be responsible for exhibiting unwanted gastro-intestinal effects (Küpeli et al., 2002). Recent mechanistic study conducted by Kuo et al. (2004) further cemented the COX-2 inhibitory activity of berberine (1). Where pretreated oral cancer cell line OC2 and $\mathrm{KB}$ cells with various concentrations $(1,10$, and $100 \mathrm{mM}$ ) of berberine (1) have shown dose dependent $\mathrm{PGE}_{2}$ inhibitory activity via suppressing the COX-2 expression. Moreover, in the same study berbarine (1) was also able to inhibit activator protein 1 (AP-1), a transcription factor responsible for producing inflammation-mediated cancers. In another study berberine (1) exhibited potent apoptotic potential in KB cells via modulating its COX-2 activity. Moreover, berberine (1) suppressed Akt phosphorylation and Mcl-1 expression which led to mark COX2 inhibition (Chi-Li et al., 2005). In light of the above facts it can be concluded that berberine (1) can be a therapeutic option in treating inflammation and COX-2 mediated cancer (Fukuda et al., 1999).

Lately a phytochemical analysis was carried out on Evodia rutaecarpa, which afforded rutaecarpine (2) (Figure 2), an alkaloid with selective COX-2 inhibitory activity. Henceforth, this study was designed to evaluate its effect on $\mathrm{PGD}_{2}$ production in bone marrow derived mast cells (BMMC) and its COX-2 mediated $\mathrm{PGE}_{2}$ inhibitory activity in HEK293 cells. The results suggested that rutaecarpine (2) able to inhibit COX-1 and COX2 mediated $\mathrm{PGD}_{2}$ production in $\mathrm{BMMC}$ at a concentration dependent manner with an $\mathrm{IC}_{50}$ value of 0.28 and $8.7 \mu \mathrm{M}$, respectively. In addition rutaecarpine (2) was also able to inhibit COX-2 mediated $\mathrm{PGE}_{2}$ production in HEK293 at same concentration range. Moreover, the study conducted by Choi et al. (2006) further cemented the anti-inflammatory activity of Evodia rutaecarpa's alkaloids. This study was designed to evaluate the anti-inflammatory activity of rutaecarpine (2) and evodiamine (3) (Figure 2). Evodiamine (3) and rutaecarpine (2) significantly inhibited $\mathrm{PGE}_{2}$ production in LPS-induced RAW 267.7 cell with an $\mathrm{IC}_{50}$ range of $1-10 \mu \mathrm{M}$. Moreover, evodiamine was also able to suppress the COX-2 expression via inhibiting NF- $\kappa \mathrm{B}$ activation. Likewise, in recent study conducted on Evodia fructus have highlighted the anti-inflammatory activity of its major quinazoline alkaloid dehydroevodiamine (4) (Figure 2). The results suggested that dehydroevodiamine (4) was able to produce mark $\mathrm{PGE}_{2}$ and $\mathrm{COX}-2$ inhibition via inhibiting the nuclear factor-kappa B (NF- $\mathrm{B}$ ) activity in LPS-induced RAW 264.7 macrophages cells. Therefore, it is strongly suggested that dehydroevodiamine (4) can serve as potent anti-inflammatory agent due to its ability to inhibit COX-2 mediated $\mathrm{PGE}_{2}$ production in LPS-activated NF-кB (Noh et al., 2006).
Isatis tinctoria is widely used by the natives of tropical rain forest as a traditional remedy against all sort of inflammatory conditions (Hamburger, 2002). Recently Danz et al. (2001) evaluated the anti-inflammatory activity of tryptanthrin (5) (Figure 2), an alkaloids widely exist in Isatis species. The results suggested that tryptanthrin (5) was significantly able to inhibit the COX-2 activity with an $\mathrm{IC}_{50}$ value $\left(\mathrm{IC}_{50}=64 \mu \mathrm{M}\right)$ comparable to that of positive control Nimisulide $\left(\mathrm{IC}_{50}=39 \mu \mathrm{M}\right)$. Moreover, similar activity was reported from recent study conducted on novel alkaloid isolated from Fissistigma cavaleriei root. The study was designed to evaluate the effect of COX-2 inhibition on angiogenesis of tumor of cells. The results suggested that pretreatment with $8,16,32,64$, and $128 \mu \mathrm{g} / \mathrm{ml}$ of compound 1 (name not specified by author) have shown potent dose dependent COX-2 inhibitory activity which led to disruption of newly formed blood vessels in chicken chorio-allantoic membrane. It the light of this study it is suggested that anti-angiogenic property of compound 1 is mainly due to its COX-2 inhibitory activity which can be use as therapeutic option in those tumors where over-expression of COX-2 play significant role (Yang et al., 2012). In another study $7^{\prime}-\left(3^{\prime}, 4^{\prime}\right.$-dihydroxyphenyl)-n[(4-methoxyphenyl) ethyl] propenamide (Z23) (6) (Figure 2), an alkaloid isolated from Fissistigma oldhamii was evaluated for its anti-inflammatory activity. The results suggested that $\mathrm{Z} 23$ has exhibited mark $\mathrm{PGE}_{2}$ inhibition via suppressing the COX-2 expression in LPS-induced RAW 264.7 macrophages (Yang et al., 2012). Moreover, Saadawi et al. (2012) reported the similar activity for the acetylmelodorinol (7) (Figure 2) isolated from Mitrella kentia. The results suggested the acetylmelodorinol was able to inhibit in $\mathrm{PGE}_{2}$ in LPSinduced human blood with an IC $_{50}$ value of $19.1 \mu \mathrm{M}$. It was proposed that acetylmelodorinol (7) exhibited $\mathrm{PGE}_{2}$ inhibition via modulating the COX-2 activity. However, more work needs to done on acetylmelodorinol in order to validate this claim.

\section{Terpenoids}

Japanese have used Acanthopanax kiusianus Nakai for centuries due to its medicinal activities. A. kiusianus is claimed to reduce neurological pain, rheumatism, inflammation of joints, and muscles (Fukuda et al., 2011). However, there were no scientific evidences to these medicinal practices. Until, Suh et al. (2001) conducted a docking study to validate anti-inflammatory activity of A. kiusianus. The results suggested that acanthoic acid (8) (Figure 3) a novel pimarane diterpene isolated from A kiusianus has the potential to inhibit COX-1 and COX-2 at a $\mathrm{IC}_{50}$ range of 116.4 and $790.4 \mu \mathrm{M}$, respectively. However, more work need to be carried on the plant species in order to validate its claimed anti-inflammatory activity. Likewise, Acanthopanax trifoliatus is famous in Southeast Asia, due its wide range of medicinal activity against lung hemorrhages, partial paralysis and neurological pain (Prajapati et al., 2003). Recently, Kiem et al. (2004) conducted phytochemical analysis which afforded one new and three old diterpene glycoside. Out of all the isolated compounds $16 \mathrm{aH}, 17$-iso-valerate-ent-kauran-19-oic acid (9) (Figure 3), ent-kaur-16-en-19-oic acid (10) (Figure 3), 
<smiles>COc1ccc2cc3[n+](cc2c1OC)CCc1cc2c(cc1-3)OCO2</smiles>

(1)

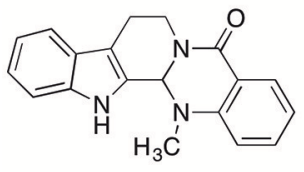

(4)<smiles>O=c1c2ccccc2nc2n1CCC1c3ccccc3NC21</smiles>

(2)<smiles>O=C1c2ccccc2N2C(=O)C3C=CC=CC3=NC12</smiles>

(5)<smiles>CC(=O)OC(/C=C1\C=CC(=O)O1)COC(=O)c1ccccc1</smiles>

(7)<smiles>CN1c2ccccc2C(=O)N2CCc3c([nH]c4ccccc34)C21</smiles>

(3)<smiles>COc1ccc(CCNC(=O)/C=C/C2CCC(O)C(O)C2)cc1</smiles>

(6)

FIGURE 2 | Structure of alkaloids with potent COX-2 and PGE 2 inhibitory activity (1) Berberine, (2) Rutaecarpin, (3) evodiamine, (4) Dehydroevodiamine, (5) tryptanthrin, (6) 7'-(3',4'dihydroxyphenyl)-n-[(4-methoxyphenyl) ethyl] propenamide (Z23), (7) acetylmelodorinol.

and ent-pimara-8(14),15-dien-19-oic acid (11) (Figure 3) have shown activity against COX-1 and COX-2 with an $\mathrm{IC}_{50}$ value of $0.21,0.15$, and $0.19 \mu \mathrm{M}$ and for COX-2 with an $\mathrm{IC}_{50}$ range of $1.1,1.2$, and $1.5 \mu \mathrm{M}$, respectively. The results from this study has provided scientific evidence for the medicinal activity of A. trifoliatus, however more animal studies should be carried out in order to validate the claimed medicinal activity (Kiem et al., 2004). Moreover, Kaurenoic acid (ent-kaur-16-en-19oic acid) (10), diterpenoid isolated from Aralia continentalis (Araliaceae) root was investigated for its anti-inflammatory activity. Kaurenoic acid was able to significantly reduce the diameter in carrageenan-induced paw edema mice model. Moreover, Kaurenoic acid (10) concentration dependently inhibited the $\mathrm{PGE}_{2}$ release with an $\mathrm{IC}_{50}$ value of $51.73 \pm$ $2.42 \mu \mathrm{M}$ via suppressing the COX-2 activity in LPS-induced RAW264.7 macrophages with $\mathrm{IC}_{50}$ value of $106.09 \pm 0.27 \mu \mathrm{M}$ respectively (Choi R. J. et al., 2011). Likewise in a recent phytochemical analysis carried out on aerial parts of Artemisia sylvatica afforded 9 sesquiterpenes. Out of all the isolated compounds arteminolide B (12) (Figure 3) was able to suppress NF- $\kappa \mathrm{B}$ mediated expression of COX-2 with an $\mathrm{IC}_{50}$ value of $7.17 \mu \mathrm{M}$. This study was first to report the anti-inflammatory activity of $A$. sylvatica via inhibiting the NF- $\kappa$ B pathway (Jin et al., 2004).

Aspergillus terreus is a widely distributed thermophilic fungus, can easily be found in soil all around the world. Recently Liaw et al. (2015) has reported to isolate two new polyketide-terpenoid from $A$. terreus. The results suggested that yaminterriterms B (13) (Figure 3) significantly inhibited the COX-2 activity with an $\mathrm{IC}_{50}$ value of $18.3 \mu \mathrm{g} / \mathrm{ml}$ in LPS-induced RAW 264.7 cells. As mentioned earlier, in past few decades various fungal species have afforded numerous bioactive chemicals with wide range of therapeutic activities. Recent study designed by Yoshikawa et al. (2005) was an effort to explore the natural products with potent anti-inflammatory activity from Fomitopsis pinicol. Out of 12 isolated compounds, fomitopinic acid A (14), fomitoside E (15), and fomitoside F (16) (Figure 3) were significantly able to inhibit COX-2 activity with an $\mathrm{IC}_{50}$ range $0.15-1.15 \mu \mathrm{M}$, as compare with positive control indomethacin with an IC50 value of $0.60 \mu \mathrm{M}$. Similarly, numerous marine based natural product have gave also interest of the researchers due to their significant anti-inflammatory activity. Specifically, marine sponges are best known for its anti-inflammatory hydroqionones (Glaser and Lock, 1995). In a recent study conducted on Cacospongia mollior have afforded two-sesterterpenoid manoalide (17) and scalaradial (18) (Figure 3). Bio-assay analysis have revealed that both compounds were able to suppress the LPS-induced $\mathrm{PGE}_{2}$ production with an $\mathrm{IC}_{50}$ value of 10.11 and $21.21 \mu \mathrm{M}$ in RAW macrophage cells respectively. Hence the results from this study have suggested that marine based products have a huge potential to serve a future lead compound for therapeutic purposes (Potts et al., 1992; Faulkner, 2001). Moreover, in a recent phytochemical analysis carried on Chinese herbal medicine have afforded three new and four known terpinpoids. Out of all the isolated 


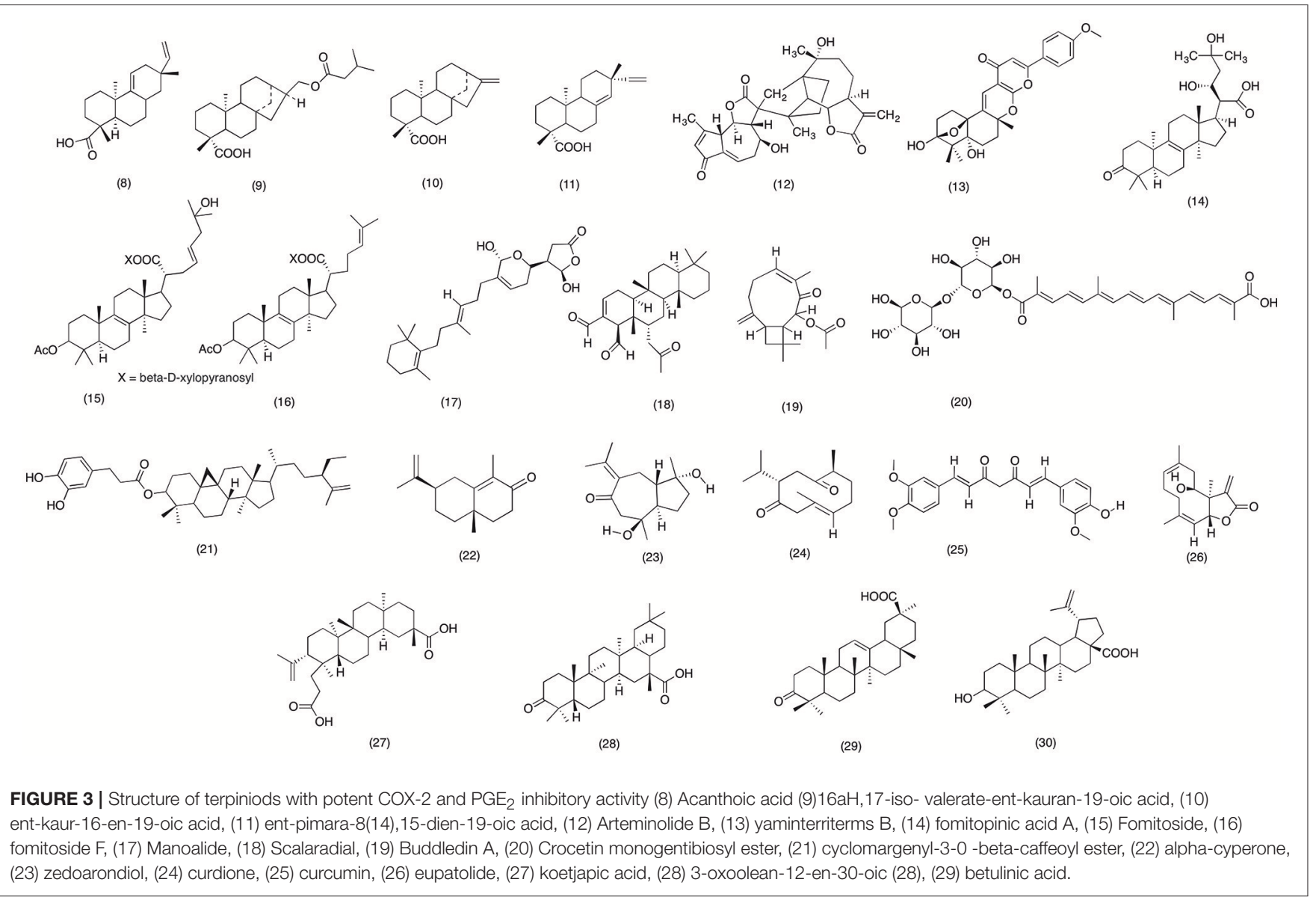

compounds buddle din A (19) and crocetin monogentibiosyl ester (20) (Figure 3) was able to inhibit COX-2 activity with an $\mathrm{IC}_{50}$ value of $13.7,28.2$ and $77.7 \mu \mathrm{M}$ respectively. Moreover, in the same study buddle din A was also able to demonstrate activity against LOX-5 with an $\mathrm{IC}_{50}$ value of $50.4 \mu \mathrm{M}$.

Costus speciosus is a widely used medicinal plant due to its potent activity against bronchitis, asthma, rheumatisms, inflammation, and fever (Katewa et al., 2004; Saraf, 2010), In recent study Al-Attas et al. (2015) evaluated the antiinflammatory of its secondary metabolites. It was reported that all the compounds have shown some degree of anti-inflammatory activity. However, 2 new terpinoids were most active against LPS-induced COX-2 mediated $\mathrm{PGE}_{2}$ production. Moreover, all tested compounds were also able to reduce the production proinflammatory cytokine including IL- $1 \beta$, IL-6, and TNF- $\alpha$. Hence this study supports the use of $C$. speciosus as traditional remedy against inflammation associated diseases. Similarly, Krameria pauciflora belongs to a small family with merely 17 plant species. However, Mexicans have been using Krameria pauciflor for hundreds of years as a traditional medicine against inflammation (Bombardelli et al., 2001; Silva et al., 2001). In recent study of Ramírez-Cisneros et al. (2012) anti-inflammatory activity of Krameria pauciflor constituents were determined. Out of all the isolated compounds cyclomargenyl-3-O- $\beta$-caffeoyl ester (21)
(Figure 3) reported the most significant $(p<0.05)$ activity against COX-2 and $\mathrm{PLA}_{2}$ with an $\mathrm{IC}_{50}$ value of $10 \mu \mathrm{M}$.

Likewise Cyperus rotundus is an Asian medicinal plant used in Chinese traditional medicine for treating various inflammatory conditions. In recent work of Jung et al. (2013) the antiinflammatory activity of $\alpha$-cyperone (22) was evaluated on LPS induced RAW macrophage cells (Figure 3). $\alpha$-cyperone (22) significantly inhibited the $\mathrm{PGE}_{2}$ production via inhibiting the COX-2 activity in LPS induced RAW macrophage cells. Moreover, pretreatment with $\alpha$-cyperone also suppressed the $\mathrm{NF}-\kappa \mathrm{B}$ activation and nuclear translocation in LPS induce cells. Hence suggesting that anti-inflammatory activity $\alpha$-cyperone is related with its ability to suppress the transcriptional activity of NF-кB. Likewise, a sesquiterpene lactone zedoarondiol (23) (Figure 3) isolated from Curcuma heyneana rhizome shared similar anti-inflammatory activity. Zedoarondiol (23) exhibited dose dependent inhibition of IL- $1 \beta$, IL- 6 , and TNF- $\alpha$ in LPSinduced macrophage cells. Moreover, expression of COX-2 and iNOS was also down regulated with the pretreatment of Zedoarondiol (23). Further mechanistic study revealed that Zedoarondiol (23) blocked the activation and transmigration of NF- $\kappa \mathrm{B}$ to the nucleus and decreasing the phosphorylation of I $\mathrm{B}$ kinase, which probably let to suppression of COX-2 expression (Cho et al., 2009). Similarly, in an effort to find 
natural products with anti-inflammatory activity, curdione (24) (Figure 3) sesquiterpenoids isolated form Curcuma zedoaria was evaluated against LPS-induced $\mathrm{PGE}_{2}$ production in RAW macrophage cells. Curdione (24) dose dependently inhibited the $\mathrm{PGE}_{2}$ production with an $\mathrm{IC}_{50}$ value of $1.1 \mu \mathrm{M}$. Further mechanistic study revealed that curdione (24) was able to decrease the $\mathrm{PGE}_{2}$ production via suppressing the COX-2 mRNA expression (Cho et al., 2009). In another study, Curcuma longa from Zingiberaceae family exhibited similar anti-inflammatory activity. It was observed that pre-treatment with $80 \mu \mathrm{g} / \mathrm{ml}$ of curcumin (25) (Figure 3) suppressed cell proliferation associated gene products (COX-2, cyclin D1, and c-myc) which led to the suppression of anti-appoptotic proteins including IAP1, IAP2, Xchromosome-linked IAP, Bcl-2, Bfl-1/A1 via blocking the TNF- $\alpha$ induced NF- $\mathrm{BB}$ activation. In a recent study conducted on Inula britannica to evaluate its anti-inflammatory reported similar NF- $\mathrm{KB}$ activity. The results have shown that eupatolide (26) (Figure 3) sesquiterpene lactone have potentially inhibited NO and $\mathrm{PGE}_{2}$ release and COX-2 and iNOS mRNA expression in a concentration dependent manner. Moreover, it was concluded that suppression of gene expression was due its ability to block NF- $\mathrm{B}$ activation, IkB degradation, MAPKs pathway and suppress Akt in LPS-stimulated RAW264.7 cells (Lee et al., 2010).

Annonaceae is among the largest planet family with more than 3,000 species. Many of its species are famous in regions of rain forest due to wide range of medicinal activities (Attiq et al., 2017). Dillenia serrate is also popular among Malaysian peninsular region due to its medicinal activity against internal hemorrhage, rheumatism, generalized body pain and inflammation (Jain, 1994; Panda, 2004). However, there are very few study conducted on this species to support its medicinal use. Hence forth in a recent study Jalil et al. (2015) evaluated a three triterpinoid koetjapic acid (27), 3-oxoolean-12-en-30oic (28), and betulinic acid (29) (Figure 3) isolated from the $D$. serrate. All the compounds exhibited significant concentrationdependent inhibitory effects on $\mathrm{PGE}_{2}$ production with $\mathrm{IC}_{50}$ values of $1.05,1.54$, and $2.59 \mu \mathrm{M}$ respectively, as compared with the positive control, indomethacin $\left(\mathrm{IC}_{50}=0.45 \mu \mathrm{M}\right)$. Moreover, it was proposed that compounds were able to inhibit the $\mathrm{PGE}_{2}$ release via modulating the COX-2 activity. However, more work need to be carried out on $D$. serrate in order to support the proposed COX-2 inhibitory mechanism. Likewise, Euphorbia nivulia belong to the Euphorbia family, which is considered as the largest family of this genera with more than 1,000 plant species. Due to its medicinal properties it has been used in Ayurveda medicine for treating rheumatism and bronchitis (Rates, 2001; Ernst et al., 2015). In late study conducted to determine the $\mathrm{PGE}_{2}$ inhibitory activity of $E$. nivulia isolates suggested that 7 -angeloyl12-acetyl-8-methoxyindol (30) (Figure 3) have shown significant $\mathrm{PGE}_{2}$ inhibition with an $\mathrm{IC}_{50}$ of $0.003 \mu \mathrm{M}$, which is comparable to the positive control Celecoxib $\left(\mathrm{IC}_{50}=0.05 \mu \mathrm{M}\right)$ (Ravikanth et al., 2002).

\section{Stilbenes}

Several plant species have been reported to have stilbenoids, a unique class of phytochemical with wide range of bioactivity (Surh, 1999). In last two decades several reports have highlighted the anticancer activity of well-established chemo-preventive secondary metabolite resveratrol (31) (Figure 4) (Jang et al., 1997; Bhat and Pezzuto, 2002). In current study usefulness of resveratrol (31) was evaluated in neurodegenerative diseases via utilizing its ability to suppress the inflammation via blocking the cyclooxygenase pathway and its components (COX and PGs). Results suggested that pretreatment with 1$50 \mu \mathrm{M}$ resveratrol (31) in LPS induced primary microglial cell significantly $(p<0.05)$ down regulated the expression of COX1 , COX-2, and mPGES- 1 in a concentration dependent manner. Hence suggesting the usefulness of resveratrol (31) in treating neurodegenerative diseases where overactive cyclooxygenase pathway plays significant role in disease progression (CandelarioJalil et al., 2007). Moreover, finding from the current study has further cemented the efficacy of resveratrol (31) in neurodegenerative diseases, (Li et al., 2012) which suggest that resveratrol (31) was able to inhibit the expression of COX-2 and mPGES-1 in LSP induced microglial cell in a concentration dependent manner. In the same study it was also observed resveratrol facilitates the non-amyloidogenic cleavage of the amyloid precursor protein which plays significant role in the clearance of amyloid beta-peptides involved in neuronal damage.

In a recent study phytochemicals of Aiphanes aculeata were evaluated for ability to suppress the COX-2 expression in various cancer cells line. It was reported that among all the isolated compounds aiphanol (32) and isorhapontigenin (33) (Figure 4) significantly inhibited COX-1 $\left(\mathrm{IC}_{50}=1.9\right.$ and $\left.1.5 \mu \mathrm{M}\right)$ and COX$2\left(\mathrm{IC}_{50} 9.9\right.$ and $\left.6.2 \mu \mathrm{M}\right)$ in a concentration dependent manner. The results suggested that aiphanol (32) and isorhapontigenin (33) (Figure 4) could be possible alternative therapeutic option for cancers ailment, as COX-2 over expression plays significant role in cancer development and progression (Lee et al., 2001). In another in vitro study oxyresveratrol (34) and artocarpesin (35) (Figure 4) isolated from Artocarpus heterophyllus, showed promising anti-inflammatory activity. Oxyresveratrol (34) and artocarpesin (35) inhibited the $\mathrm{NO}$ and $\mathrm{PGE}_{2}$ production in LPS-induced RAW 264.7 cells via suppressing the expression of the iNOS and COX-2 respectively. Which signify their role as a potential therapeutic candidate for treating inflammation mediated diseases (Fang et al., 2008).

In Chinese traditional medicine root and leaves of Hovenia dulcis are used as a traditional remedy to treat peptic ulcers, liver toxicity and inflammation (An et al., 1999; Kim et al., 2014). However, there were lack of scientific evidence for these traditional practices until Lim et al. (2015) carried out anti-inflammatory studies on the secondary metabolites of H. dulcis to validate this claim. The results suggested that methanol extract of $H$. dulcis reduced the release and production of $\mathrm{PGE}_{2}, \mathrm{IL}-4$, and TNF- $\alpha$ in a concentration dependent manner. Moreover, in the same experiment the methanolic extract of $H$. dulcis suppressed the COX-2 expression via blocking the NF- $\mathrm{KB}$ activation. The phytochemical analysis of $H$. dulcis extract revealed that pinosylvin (36) (Figure 4) was mainly responsible for the producing the inhibitory activities of methanolic extract. Similarly Rheum undulatum, another plant species from Chinese traditional medicine was subjected to the phytochemical analysis, which afforded 
<smiles>Oc1ccc(/C=C/c2cc(O)cc(O)c2)cc1</smiles>

(31)<smiles>Oc1cc(O)cc(/C=C/c2ccc(O)cc2O)c1</smiles>

(34)<smiles>COc1cc([C@H]2Oc3cc(/C=C/c4cc(O)cc(O)c4)ccc3O[C@H]2CO)cc(OC)c1O</smiles>

(32)<smiles>COc1cc(/C=C/c2cc(O)cc(O)c2)ccc1O</smiles>

(33)<smiles>COc1ccc(/C=C/c2cc(O)cc(O)c2)cc1</smiles>

(37)

FIGURE 4 | Structure of stilbenes with potent COX-2 and PGE 2 inhibitory activity (31) transresveratrol, (32) aiphanol, (33) isorhapontigenin, (34) oxyresveratrol, (35) artocarpesin, (36) pinosylvin, (37) desoxyrhapontigenin.

desoxyrhapontigenin (37) (Figure 4). Bioassay analysis showed that desoxyrhapontigenin (37) significantly decreased the NO and $\mathrm{PGE}_{2}$ production at a concentration range of $10-50 \mu \mathrm{M}$. Additionally, it was observed that desoxyrhapontigenin was also able to suppress the expression of iNOS and COX-2 by blocking the LPS- induced NF- $\kappa \mathrm{B}$ activation in RAW macrophage cells (Choi et al., 2014). This study suggests that desoxyrhapontigenin (37) has the potential to resolve inflammation by suppressing the expression of inflammatory mediators via blocking the transcriptional activity of NF- $\kappa$ B.

\section{Flavonoids}

Artemisia feddei is widely used in African countries due to its ornamental and medicinal uses (Kim et al., 1999). The bark and leave decoction has been used as traditional remedy for digestive and inflammatory disorder (Kang et al., 1999). In recent study, Kim et al. (2004) reported the anti-inflammatory activity of scopoletin (38) (Figure 5) isolated from A. feddei. Pretreatment with $1-50 \mu \mathrm{g} / \mathrm{ml}$ of scopoletin (38) was able to significantly inhibit the production of $\mathrm{PGE}_{2}$, TNF- $\alpha$, IL- $1 \beta$, and IL- 6 in a concentration dependent manner. Further studies suggested that scopoletin (38) inhibited the $\mathrm{PGE}_{2}$ production via inhibiting the LPS-induced COX-2 activity in RAW 264.7 macrophages. Likewise, Noreen et al. (1998) evaluated the anti-inflammatory activity of the flavonoids obtained from various medicinal plants including Atuna racemosa, Syzygium corynocarpum, Syzygium malaccense, and Vantanea peruviana. Among all the isolated flavonoids (+)-catechin (39), (+)-gallocatechin (40), 4'-O-Me-ent-gallocatechin (41), ouratea-catechin (42), and proanthocynidin A (43) (Figure 5) demonstrated inhibition of
COX-2 activity with an $\mathrm{IC}_{50}$ range from 3.3 to $138 \mu \mathrm{M}$. These results suggested that medicinal activities of these plants extracts were due to the COX-2 inhibitory activity of its flavonoids. Unlike the previous studies conducted on perennial plant species, Ogundaini et al. (1996) focused on a parasitic plant Sarcophyte piriei, which proliferates on the roots of Acacia species. There are several reports which signifies the medicinal activity of this parasitic species against abdominal pain, toothache, and burses (Pongprayoon et al., 1991; Farah and Samuelsson, 1992). However, the phytochemical and pharmacological profile of this plane specie is not well-established. Hence Ogundaini et al. (1996) designed study to evaluated the phytochemistry and anti-inflammatory activity of $S$. piriei. The phytochemical analysis revealed two new flavonoid c (44) and diinsinin (45) (Figure 5) and pharmacological screening suggested that both compounds had excellent $\mathrm{PGE}_{2}$ inhibitory activity with $\mathrm{IC}_{50}$ values 9.20 and $13.14 \mu \mathrm{M}$, respectively. Moreover, upon further analysis both flavonoids suppressed PAF induced exocytosis with $\mathrm{IC}_{50}$ values 49 and $39 \mu \mathrm{M}$. In conclusion it was proposed that these compounds were able to inhibit $\mathrm{PGE}_{2}$ production via attenuating the COX-2 activity in LPS induced RAW macrophage cells. Likewise, in a recent study anti-inflammatory activity of Chrysopogon aciculatis was also evaluated in LPSinduced RAW macrophage 264.7 cells. The phytochemical analysis of acetone fraction of $C$. aciculatis afforded aciculatin (46) (Figure 5). The bioassay results demonstrated potent $\mathrm{PGE}_{2}$ and NO inhibitory activity of aciculatin (46) with an $\mathrm{IC}_{50}$ range of $1-10 \mu \mathrm{M}$. Aciculatin (46) was also able to suppress the expression of iNOS and COX-2 via inhibiting the activation and translocation of NF-кB in LPS-induced RAW 264.7 cells. 
Moreover, aciculatin (46) was also able to suppress IкB kinase activation and phosphorylation of MAPKs. Hence suggested the anti-inflammatory activity of aciculatin (46) was due to its ability to suppress the transcriptional activity of NF- $\mathrm{\kappa B}$ and MAPKs (Hsieh et al., 2011). Francis et al. (2004) reported the similar COX-2 suppressing activity of Kaempferol, isolated from Easter lily (Lilium longiflorum) flowers. In lipid peroxidation inhibitory assay kaempferol (47) strongly inhibited the COX-2 activity by $36.9 \%$ at $80 \mathrm{ppm}$. While it was observed that the inhibitory activity was not concentration dependent since in the same experiment kaempferol (47) inhibited COX-2 activity by $37 \%$ at $1 \mathrm{ppm}$, while $100 \%$ COX-2 inhibition was observed at 10 ppm respectively. However, in another study delphinidin 3-Obeta-galactopyranoside, cyanidin 3-O-beta-galactopyranoside, and pelargonidin 3-O-beta-galactopyranoside, three novel anthocyanins failed to show any significant anti-inflammatory activity. It was reported that all the tested compounds were only able to inhibit COX 1 by $9.23,11.71$, and $7.66 \%$ with an $\mathrm{IC}_{50}$ values ranging $40-170 \mu \mathrm{M}$. While isolated compounds merely inhibited COX-2 activity by $7.65,12.46$, and $7.38 \%$ at the same concentrations. Hence anti-inflammatory activity of these compounds were considered insignificant, as compare to the positive control used in the experiment (Naproxen) (Seeram et al., 2002). Moreover, in a recent study carried out on in order to investigate the mechanism to action through which bacterial endotoxins and cytokines induce the gene expression of COX-2 and mPGES-1, which are directly related to the increases turn over of $\mathrm{PGE}_{2}$ in macrophages and other tissues. Out of 24 naturally occurring flavonoids tested kaempferol (47) most significantly suppressed the LPS induced COX-2 and mPGES- 1 with an $\mathrm{IC}_{50}$ value of 1.89 and $5.81 \mu \mathrm{M}$, as compare to Celecoxib ( $\mathrm{IC}_{50} 1.11$ and 4.98) known selective COX-2 inhibitor (Hämäläinen et al., 2011). In order to explore the natural product with anti-inflammatory activity, gigantol (48) (Figure 5) isolated from Cymbidium goeringii was evaluated against $\mathrm{PGE}_{2}$ and $\mathrm{NO}$ production in LPS induced RAW 264.7 cells. The results indicated that gigantol (48) inhibited $\mathrm{NO}$ and $\mathrm{PGE}_{2}$ production in a concentration dependent manner. In addition gigantol (48) reduced the production and expression of major pro-inflammatory cytokines including TNF- $\alpha$, IL-1 $\alpha$, and IL-6. Moreover, gigantol (48) also suppressed COX-2 and iNOS expression via blocking the LPS-induce NF- $\kappa \mathrm{B}$ activation in a concentration dependent manner. Hence it was proposed that gigantol (48) was able to suppress the gene expression of COX-2 and iNOS via blocking the transcriptional activity of the activation of NF- $\kappa$ B. Likewise, Hiermann et al. (1998) evaluated the anti-inflammatory activity of myricetinglucuronide (49) (Figure 5) on acute (carrageenan) and chronic (adjuvant arthritis) rat model. COX-2 inhibitory activity was evaluated on perfused rabbit ear. myricetinglucuronide (49) was able to reduce inflammation in both acute and chronic inflammation model with an $\mathrm{ED}_{50}$ value of 15 and $150 \mu \mathrm{g} / \mathrm{kg}$, respectively. Pretreatment with $1 \mu \mathrm{g} / \mathrm{ml}$ myricetinglucuronide (49) significantly reduced the production of $\mathrm{PGI}_{2}, \mathrm{PGE}_{2}$, and $\mathrm{PGD}_{2}$ in perfused rabbit ear. Moreover, myricetinglucuronide (49) was also able to suppress the activity of COX-1 and COX-2 with $\mathrm{IC}_{50}$ values 9.2 and $2.4 \mu \mathrm{M}$, respectively. This study highlighted the anti-inflammatory of myricetinglucuronide in both in-vivo and in-vitro models signifying the myricetinglucuronide (49) as potential therapeutic option for resolving inflammation.

Soya bean has been reported to have anti-cancer activity due to presence of genistein (50) (Figure 5). Ye et al. (2004) tested genistein (50) on a human oral squamous carcinoma line (SCC-25) for the evaluation of anti-cancer potential in COX2 mediated cancers. The results demonstrated that genistein (50) have shown significant cytotoxic activity in both cancer cell line, however it failed to exhibit apoptotic potential in the same study. Moreover, genistein (50) also inhibited the enzymatic activity and expression of COX-2 in a dose dependent manner. This study suggests that genistein can serve as potential chemo-protective agents in COX-2 mediated cancers. In another phytochemical study conducted on soya bean afforded anthocyanin (51) (Figure 5), a flavanoid with potent anticancer activity (Wang and Stoner, 2008). It was observed that pretreatment with anthocyanin (51) exhibited significant reduction in $\mathrm{PGE}_{2}$ production in LPS-induced human keratinocyte. Moreover, anthocyanin also blocked the activation of NF- $\mathrm{KB}$ and PI3 kinases in UVB exposure human keratinocyte cells. Likewise, Pan et al. (2008) reported the similar activity for two flavonoids, tectorigenin (52) and tectoridin (53) (Figure 5) isolated from Iris domestica. The current study was designed to evaluate the anti-inflammatory activity of these two flavonoids in LPS induced/interferon- $\gamma$ induced RAW 264.7 macrophage cells. Tectorigenin (52) significantly inhibited the production of $\mathrm{NO}$ and $\mathrm{PGE}_{2}$ through suppressing the expression of iNOS and COX-2 in a concentration dependent manner. Moreover, the pretreatment with tectorigenin (52) was also able to block the activation of NF- $\mathrm{kB}$ with an $\mathrm{IC}_{50}$ value comparable to that of positive control genistein.

Prenylated flavonoids are widely distributed flavonoids with a combination of 1,1-dimethylallyl, an isoprenyl unit a geranyl unit attached together in one structure., Chi et al. (2001b) managed to isolate 19 prenylated flavonoids from Morus alba and then evaluated their inhibitory activity against COX-1, COX-2, and 5-LOX. The results suggested that among all the tested flavonoids morusin (54), kuwanon C (55), sanggenon B (56), and sanggenon C (57) (Figure 5) had shown significant inhibitory activity against $\mathrm{COX}-2$ with an $\mathrm{IC}_{50}$ value ranging 73-100 $\mu \mathrm{M}$. However, most of the compounds were more active $\left(\mathrm{IC}_{50}=0.1\right.$ to $\left.1 \mu \mathrm{M}\right)$ against COX-1 rather then COX2 , hence making them inappropriate for therapeutic use due to gastrointestinal effects associated with COX-1 inhibition. Another study suggested that sanggenon D (58) and B (56) (Figure 5) isolated from Morus mongolica exhibited similar COX-1 and COX-2 activity with IC $_{50}$ values of 59 and $42 \mu \mathrm{M}$ for COX-1 and 73 and $100 \mu \mathrm{M}$ for COX-2 inhibition. Likewise, screening of bioactive isolates carried out by Huang et al. (2016) to establish novel method of orthogonal projection to latent structure and modified principal component analysis revealed that wogonin (59) and oroxylin A (60) (Figure 5), major component of Scutellaria baicalensis significantly inhibited the $\mathrm{PGE}_{2}$ production in RAW 264.7 macrophages. Furthermore, similar activity was reported by another study carried out by 


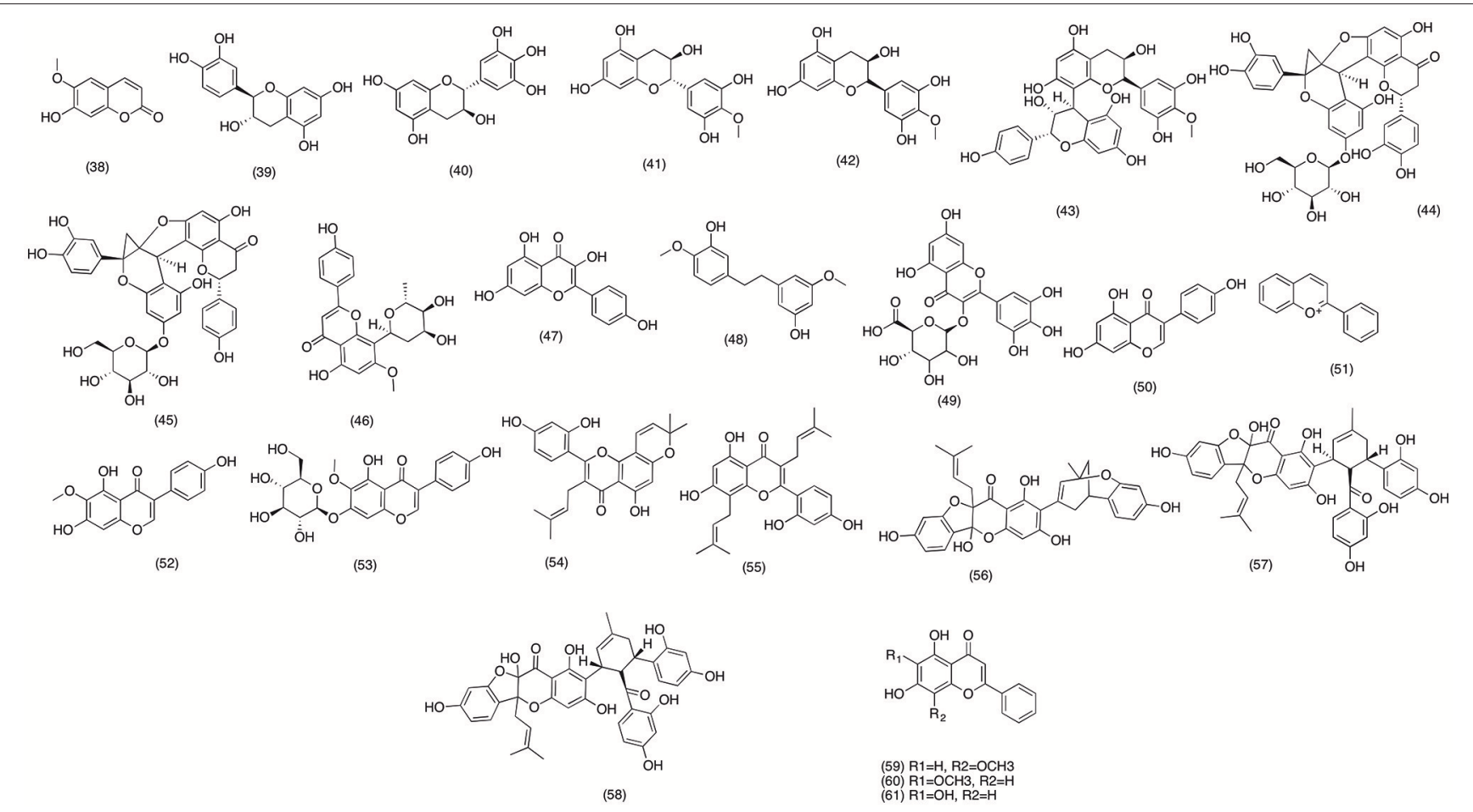

FIGURE 5 | Structure of flavanoids with potent COX-2 and PGE 2 inhibitory activity (38) scopoletin, (39) (+)-catechin, (40) (+) gallocatechin, (41) 4' -0-Me-entgallocatechin, (42) ouratea-catechin, (43) proanthocynidin A, (44) flavonoid c, (45) diinsinin, (46) aciculatin, (47) kaempferol, (48) gigantol, (49) myricetinglucuronide, (50) genistein, (51) anthocyanin, (52) tectorigenin, (53) tectoridin, (54) morusin, (55) kuwanon C, (56) sanggenon B, (57) sanggenon C, (58) sanggenon D, (59) wogonin, (60) oroxylin A, (61) baicalein.

Fernando et al. (2016) to evaluate the anti-inflammatory activity of baicalein (61) (Figure 5) from marine source. The results from this study suggested that baicalein (61) exhibited antiinflammatory activity via modulating the gene expression of major inflammatory mediators including IL-1, MCP1, COX-2. In the same study baicalein (61) was also able to suppress the activity of anti-apoptotic proteins including cIAP-1, cIAP-2, and FLIP. Moreover, it was suggested that the reported activity was due to the inhibition of TNF-a induced NF- $\kappa$ B, p65 nuclear translocation and inhibition of phosphorylation and degradation of IkBa.

\section{Saponins}

Artemisia capillaris is widely used plant species all around the world to treat pain, inflammation and alcohol induced liver toxicity (Bora and Sharma, 2011; Joshi, 2013). A recent study was carried out to evaluate the anti-inflammatory and analgesic activity of capillarisin (62) (Figure 6), a major lignin isolated from A. capillaris. The major scope of this study was to evaluate the capillarisin (62) activity against MyD88/TIRAP, iNOS, and COX-2 at therapeutic concentrations. It was observed that pretreatment with capillarisin (62) significantly inhibited the LPS- induced activation of NF-кB, Akt, and MAPKs mediated inflammatory genes. Moreover, it was also observed that pretreatment with capillarisin was able to reduce the expression of COX-2 and iNOS in LPS-induced RAW 264.7 macrophage cells. In the same study, capillarisin (62) also significantly blocked the activation of p-JNK, p-p38, pERK, and p-Akt. Hence it was concluded form the present study that the potent anti-inflammatory activity of capillarisin (62) was via inhibiting the activation pathways responsible for promoting the activity of inflammatory mediators (Khan et al., 2013). Moreover, a similar study was carried out on an ornamental plant species Kalopanax pictus, to evaluate the anti-inflammatory activity of its constituents. Out of all the tested compounds it was observed that monodesmosides (63) (Figure 6) and kalopanxsaponin-A (64) (Figure 6) most significantly inhibited the NO, $\mathrm{PGE}_{2}$, and TNF- $\alpha$ production in LPS- induced RAW 264.7 macrophage cells (Kim Y. K. et al., 2002).

Araliaceae family consists of numerous species with potent medicinal activities. Ginseng is most widely consumed medicinal plant from this plant family due to its medicinal activities (Corbit et al., 2005; Park et al., 2005). Ginseng can be used as fresh, dried (white ginseng) or peeled form (red ginseng). However, recent studies have suggested that all forms of ginseng have equal medical activity irrespective of their mode of administration or part used (Kang et al., 2005; Volate et al., 2005). There are several reports which suggest the antiinflammatory activity of ginseng, including most recent study of Ichikawa et al. (2009) reported that ginsing extract and ginsenosides (65) (Figure 6) were able to inhibit the activation of NF- $\mathrm{B}$ and MAPKs. Moreover, ginsenosides (65) exhibited potent activity against $\mathrm{PGE}_{2}$ and $\mathrm{NO}$ via suppressing the COX-2 
<smiles>COc1c(O)cc2oc(Oc3ccc(O)cc3)cc(=O)c2c1O</smiles>

(62)

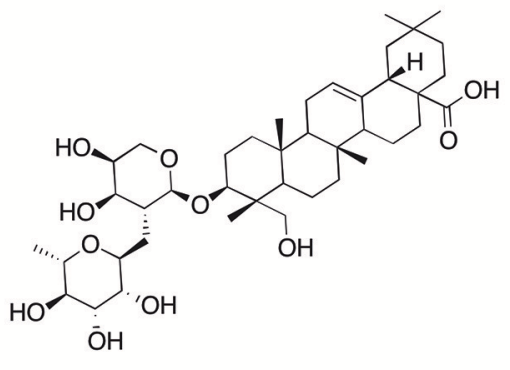

(64)

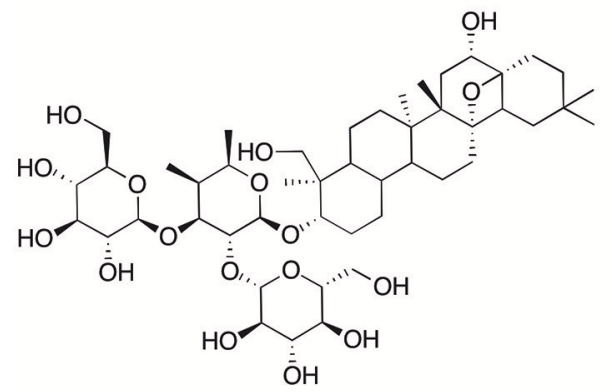

(66)<smiles>O=C(/C=C/c1ccc(O)c(OC2OC(CO)[C@@H](O)[C@H](O)[C@H]2O)c1)c1ccc(O)cc1O</smiles>

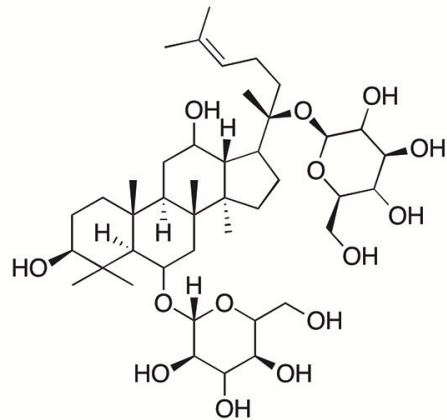

(65)

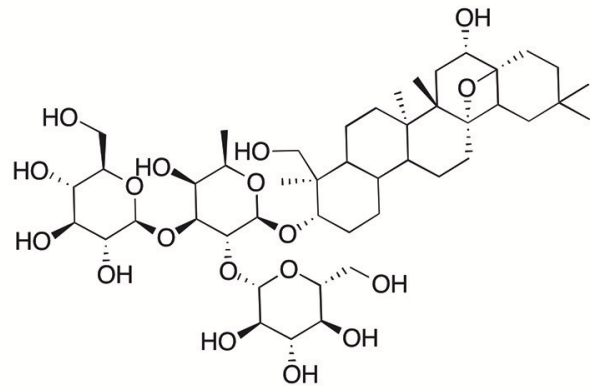

(67)

FIGURE 6 | Structure of saponins with potent COX-2 and PGE 2 inhibitory activity (62) capillarisin, (63) monodesmosides, (64) kalopanxsaponin-A, (65) ginsenosides, (66) saponin prosapogenin D methyl-ester, (67)buddlejasaponin I.

and iNOS activity in LPS induced macrophage cells. Moreover, in another study conducted to evaluate the anti-inflammatory activity of ginsenosides (65) suggested that pretreatment with ginsenosides (65) led to down regulation of COX-2 in a concentration dependent manner. Further mechanistic study revealed that ginsenosides (65) was able to pull out this activity via suppressing the transcriptional property of NF- $\kappa$ B (Hofseth and Wargovich, 2007). Likewise in another report ginsenoside (65) was evaluated for its anti-inflammatory in neurodegenerative disorder including Parkinson diseases. The results suggested that ginsenoside (65) was able to reduce the $\mathrm{PGE}_{2}$ and $\mathrm{NO}$ production via suppressing the COX-2 and iNOS expression hence signifying its importance in treating those neurodegenerative diseases where excessive activity of $\mathrm{PGE}_{2}$, NO, and COX-2 plays significant role (Zhang et al., 2006).

Platycodon grandiflorum belong to Campanulaceae family and the root this species (Platycodi Radix) is widely consumed all around the world as a traditional medicine for lungs infection and ocular inflammation (Ahn et al., 2005; Srivastava et al., 2005). These traditional practices are consistent with the existence of high content of saponin present inside this species (Shin et al., 2002). In a recent study new saponin prosapogenin D methyl-ester (66) (Figure 6) isolated form Platycodi radix and was evaluated for possible anti-inflammatory activity. It was observed that prosapogenin D methyl-ester (66) was able to reduced the biosynthesis of $\mathrm{NO}$ and $\mathrm{PGE}_{2}$ in a concentration dependent manner. Furthermore, D methyl-ester significantly down regulated COX-2 and iNOS expression via completely blocking the activation of NF- $\kappa \mathrm{B}$ in LPS induced RAW macrophage 264.7 cells (Chung et al., 2008). Similar activity was reported for new saponins buddlejasaponin IV (67) (Figure 6) isolated from Pleurospermum kamtschaticum. Where buddlejasaponin IV (67) potentially inhibited the production of $\mathrm{PGE}_{2}$, TNF- $\alpha$, and NO in LPS induced RAW 264.7 macrophage cells.

\section{Fatty Acids}

Daucus carota is most widely consumed vegetable around the world. Some parts of the world use it as ornamental medicine for digestive disorders, cardiovascular disorders, epilepsy, and infertility (Momin et al., 2003). Recent studies have suggested 
that high content of essential oils present inside the carrot are responsible for the most of the medicinal activities. Momin et al. (2003) designed a study to determine the antiinflammatory activity of essential oils isolated from D.carota. The results suggested that 2,4,5-trimethoxybenzaldehyde (68), oleic acid (69), and trans-asarone (70) (Figure 7) had inhibited the COX-2 activity by $52.69,68.41$, and $64.39 \%$. While all three compounds did not show any significant activity against COX-1. In conclusion, 2,4,5-trimethoxybenzaldehyde (68) most significantly inhibited COX-2 in a concentration dependent manner with an $\mathrm{IC}_{50}$ value of $100 \mu \mathrm{g} / \mathrm{ml}$. Likewise form prehistoric times humans have been using mushrooms in daily routine due to their nutritional and medicinal value. One of the most widely consumed mushrooms includes Grifola frondosa, which is commonly referred as hen of the woods due to characteristic shape and texture. G. frondosa is also one of the main ingredients in Chinese traditional medicine prepared for treating hemorrhoids (Huang and Xie, 1988), gonorrhea (Mizuno and Zhuang, 1995), diabetes (Kubo et al., 1994), neuralgia, and arthritis (Mizuno and Zhuang, 1995). A study by Zhang et al. (2002) was designed to evaluate the potential antiinflammatory activity of essential oils isolated from $G$. frondosa. It was observed that hexane fraction consisting ergosterol (71), ergostra-4,6,8(14),22-tetraen-3-one (72), and 1-oleoyl-2linoleoyl-3-palmitoylglycerol (73) (Figure 7) has significantly inhibited the COX-1 activity by 98,37 , and $67 \%$ at $250 \mu \mathrm{g} / \mathrm{ml}$. Likewise upon further analysis it was revealed that all the compounds were also able to inhibit COX-2 activity by 99 , 37 , and $70 \%$ at $250 \mu \mathrm{g} / \mathrm{ml}$, respectively. This study provides evidence of bioactive compounds responsible for producing medicinal activities against inflammatory conditions. Moreover, a recent at study by Wang et al. (2017) further highlighted the anti-inflammatory activity of edible mushroom, which led to the isolation of eburicoic acid (74) (Figure 7) from Laetiporus sulphureus. The study demonstrated that eburicoic acid (74) was able to reduce the $\mathrm{PGE}_{2}$ and $\mathrm{NO}$ production via suppressing the expression of iNOS and COX-2 in LPSinduced RAW 264.7 macrophage cells. Moreover, it was observed that eburicoic acid (74) significantly inhibited the production of TNF- $\alpha$, IL- 6 , and IL- $1 \beta$ and down regulated the expression of PI3k, Akt, mTOR, and NF- $\mathrm{Bp} 65$. Hence suggesting that eburicoic acid (74) has potent anti-inflammatory activity via suppressing the inflammatory pathways and inhibiting the production of pro-inflammatory cytokines (Wang et al., 2017). Moreover, Paul et al. (2006) reported the similar activity for the 13-(S)-hydroxy-9Z,11E-octadecadienoic acid [(S)-coriolic acid (75) (Figure 7) isolated from Hernandia ovigera L. The results suggested that 13-(S)-hydroxy-9Z,11E-octadecadienoic acid [(S)-coriolic acid (75) shown selective COX-2 inhibition with an $\mathrm{IC}_{50}$ Value of $0.30 \mu \mathrm{M}$. However, it was observed that upon increasing the concentration 13-(S)-hydroxy-9Z,11Eoctadecadienoic acid [(S)-corioli acid (75) have lost its COX-2 selectivity and also exhibited COX-1 inhibition at concentrations $>100 \mu \mathrm{M}$. Moreover, it has the tenacity to suppress the expression of iNOS, COX-2, IL-6, and TNF-a by blocking the activation of NF- and AP-1 activator protein. Furthermore, phytochemical analysis of Hernandia ovigera afforded palmitic acid (76), oleic acid (77), linoleic acid (78), linolenic acids (79) (Figure 7). This study was designed to evaluate the antiinflammatory of fatty acid that make up the major composition of Hernandia ovigera. All the compounds have shown significantly inhibited the COX-2 activity in a concentration dependent manner with an $\mathrm{IC}_{50}$ range of 10.5 to $23.0 \mu \mathrm{M}$ (Bauer et al., 1996).

\section{Miscellaneous Compounds}

Acanthopanax species have been used in far East-Asian countries to cure rheumatoid arthritis and diabetes mellitus (Kim and Hahn, 1981; Lee S.-H. et al., 2003). A recent study was carried out to evaluate the anti-inflammatory activity of the lignins isolated from Acanthopanax chiisanensis. It was observed that out of five lignins isolated, taiwanin C (80) (Figure 8) dose dependently inhibited the $\mathrm{PGE}_{2}$ production with an $\mathrm{IC}_{50}$ value of $0.12 \mu \mathrm{M}$ while other four lignin failed to show any activity at given concentrations (Lee et al., 2005). Likewise balanophonin (81) (Figure 8), a neolignin isolated from Firmiana simplex was evaluated for its ability to reduce neuro-inflammation. This study suggested that balanophonin $(\mathbf{8 1})$ reduced the production of TLR4, NO, PGE 2 , IL- $1 \beta$, and TNF- $\alpha$ in LPS induced BV2 cells. Moreover, it was also observed that pretreatment with balanophonin also dose dependently suppressed iNOS, COX2, and MAPKs expression. In the light of this study it could be inferred that balanophonin has the potential to reduce the neuronal cell death by inhibiting microglial activation (Lim et al., 2017). Likewise, Withania somnifera is an ever green shrub extensively used in Ayurvedic medicine for treating adenopathy, arthritis, inflammations, and rheumatism (Thakur et al., 1989; Rasool and Varalakshmi, 2006). Withanolides are a specific class of compounds associated with $W$. somnifera, which is responsible for carrying out above stated medicinal activities (Ray and Gupta, 1994). In a recent study withanolide glycosides and withanolided isolated from $W$. somnifera were subjected to anti-inflammatory evaluation. Out of all the isolated compounds sitoindoside IX (82) (Figure 8) most significantly inhibited the COX-2 activity with an $\mathrm{IC}_{50}$ value of $100 \mathrm{mg} / \mathrm{ml}$. while rest of the compounds exhibited non-selective COX inhibition. Likewise, in anti-proliferative study conducted by Mulabagal et al. (2009) reported similar activity for the withanolide sulfoxide (83) (Figure 8) isolated from $W$. somnifera. It was observed that withanolide sulfoxide selectively inhibited COX-2 activity by $60 \%$ with an $\mathrm{IC}_{50}$ value of $100 \mu \mathrm{M}$. Moreover, upon further evaluation withanolide sulfoxide (83) have also shown potent anti-proliferative activity in various cancer cell lines [human gastric (AGS), breast (MCF-7), central nervous system (SF268), and colon (HCT-116)] with an $\mathrm{IC}_{50}$ range of $0.74-$ $3.63 \mu \mathrm{M}$. It was concluded form the study that COX-2 mediated anti-proliferation was responsible for the cytotoxic activity of withanolide sulfoxide (83) (Mulabagal et al., 2009). Moreover, gingerol (84) (Figure 8) is polyphenolic compound, which can be found in majority of Zingiberaceae species. A study was designed to evaluate the effect of gingerol on streptozotocin induced Alzheimer diseases in vivo by using whiskers rat model. The basic purpose of the study was to determine that whether the treatment with gingerol can to reduce the inflammation and improve 
<smiles>CCCCCCCCC/C=C\CCCCCCCC(=O)O</smiles>

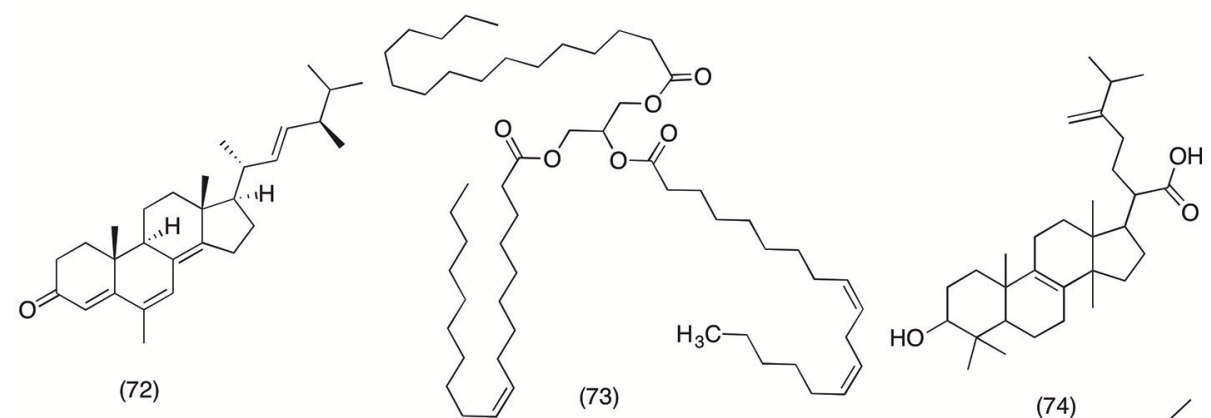

(72)

(73)

(74)<smiles>CCCCCC(O)/C=C/C=C/CCCCCCC(=O)O</smiles><smiles>CCCCCCCCCCCCCCCCCCCCCCCCC</smiles>

(76)<smiles>CCCCC/C=C\C/C=C\CCCCCCCC(=O)O</smiles>

(78)<smiles>CC/C=C\C/C=C\C/C=C\CCCCCCCC(=O)O</smiles>

(79)

FIGURE 7 | Structure offatty acids with potent COX-2 and PGE 2 inhibitory activity (68) 2,4,5-trimethoxybenzaldehyde, (69) oleic acid, (70) trans-asarone, (71) ergosterol, (72) ergostra-4,6,8(14),22-tetraen-3-one, (73) 1-oleoyl-2-linoleoyl-3-palmitoylglycerol, (74) eburicoic acid, (75) 13-(S)-hydroxy-9Z,11E-octadecadienoic acid [(S)-coriolic acid, (76) palmitic acid, (77) oleic acid, (78) linoleic acid, (79) linolenic acids.

the cognitive impairment in sporadic Alzheimer's disease in whiskers rat model. The results suggested that pretreatment with 10 and $20 \mathrm{mg} / \mathrm{kg}$ bwt significantly reduce the $\alpha-, \beta$ secretases, APH1a and COX-2 levels, which resulted in the improvement of cognitive behaviors (El Halawany et al., 2017). Likewise similar activity was reported for two styryllactone, altholactone (85) and (+)-goniothalmin (86) (Figure 8) isolated from Alphonsea javanica. It was concluded form the current study that both compounds significantly reduced the LPSinduced NO production, phosphorylation of IKB alpha, and also down regulated the gene expression of iNOS and COX2 (Johnson et al., 2013). Moreover, diglyceride (87) from Amaranthus tricolor were also able to inhibit the COX-1 enzyme by 78,63 , and $93 \%$, respectively and the COX-2 enzyme by 87 , 74, and 95\%, respectively (Jayaprakasam et al., 2004). However, due to their non-selective COX activity, it is expected that use of these diglyceride (87) might be associated with undesirable gastrointestinal effects, which limits its use as therapeutic application. Ligustilide (88) (Figure 8), phthalide derivative from Angelica tenuissi was also subjected to anti-inflammatory evaluation. The bioassay results demonstrated that Ligustilide (87) has potent anti-inflammatory activity by modulating NF$\kappa \mathrm{B}$ and MAPK pathways, which led to the suppression of LPSinduced iNOS and COX-2 expression at both mRNA and protein levels. Furthermore, Ligustilide (88) additionally inhibited the phosphorylation of $\mathrm{IkBa}$ and p38 mitogen-activated protein kinase in a dose dependent manner (Chung et al., 2012). Bruceine D (89) (Figure 8), belong to unique class of compound, which is mostly predominant in Simaroubaceae family. Till this date the pharmacological profile on this class is yet to be established. However, in recent study bruceine $\mathrm{D}$ showed significant inhibitory activity against COX-2 with an $\mathrm{IC}_{50}$ value of $20.6 \mu \mathrm{M}$ demonstrating the anti-inflammatory potential of this unique class ( $\mathrm{Su}$ et al., 2002). Likewise corresponding activity 
<smiles>O=C1OCc2cc3cc4c(cc3c(-c3ccc5c(c3)OCO5)c21)OCO4</smiles><smiles>COc1cc(C2Oc3c(OC)cc(/C=C/C=O)cc3[C@@H]2CO)ccc1O</smiles>

(81)

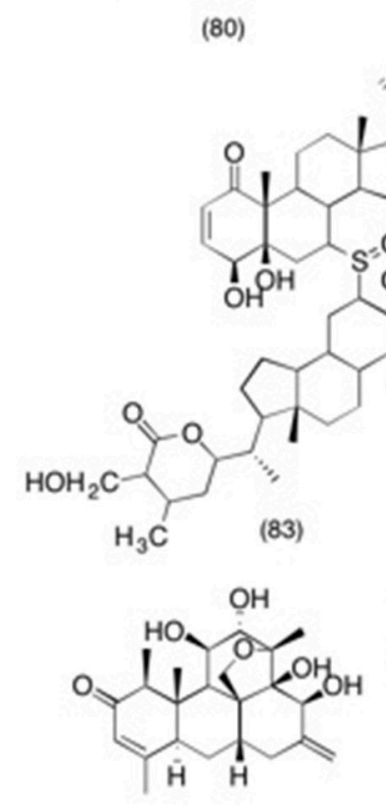

(89)

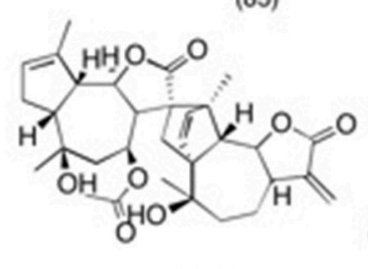

(90)<smiles>CCCCCC(O)CC(=O)CCc1ccc(O)c(OC)c1</smiles>

(84)<smiles>CCCCCCCC1(C)CCCC1C(C)[C@H]1CC=C(COC2OC(CO)[C@H](O)[C@H](O)C2O)C(=O)O1</smiles>

(82)<smiles></smiles>

(88)<smiles>C=CCc1ccc(-c2ccc(OC)c(CC=C)c2)c(-c2ccc(O)c(OC)c2CC=C)c1</smiles>

FIGURE 8 | Sturcture of miscellaneous with potent COX-2 and PGE 2 inhibitory activity (80) taiwanin C (81), balanophonin (82), sitoindoside IX (83), withanolide sulfoxide (84), gingcrol, (85) altholactone (86), goniothalmin (87), diglyccride (88), ligustilide (89), bruceine D (90), bandelin (91), guggulstcrone (92), isoliquiritin (93), isoliquiritigenin (94), sphondin (95), 4-Methoxyhonokol (96), Schisandrin (97), bocravinone B.

was observed in a study conducted on handelin (90) (Figure 8), duaianolide dimer isolated from Chrysanthemum boreale. It was observed that handelin (90) suppressed $\mathrm{NO}$ and $\mathrm{PGE}_{2}$ activity via suppressing the iNOS and COX-2 expression in LPS-induced RAW 264.7 macrophage cells. In addition, pretreatment with handelin (90) also deceased the production of IL-1 $\beta$ and TNF- $\alpha$ in a dose dependently manner. Further mechanist study revealed that handelin (90) also inhibited the activation and translocation of NF- $\mathrm{KB}$ into the nucleus, which is in complete conjunction with the suppression of COX-2 and iNOS activity.
Commiphora mukul resins have gain great importance in Ayurvedic medicine due to its wide range of medicinal properties (Craig, 1997). It has been use by Indians for centuries for treating arthritic pain, inflammation, high cholesterol, and osteoarthritis (Gujral et al., 1960; Sharma, 1977; Sinal and Gonzalez, 2002; Urizar and Moore, 2003). Recent studies have shown that guggulsterone (91) (Figure 8) isolated from Commiphora muku were able to block the activation of NF$\kappa \mathrm{B}$ in TNF- $\alpha$ induced epithelial and leukemia cells. In addition guggulsterone (91) also suppressed the phosphorylation and 
consequent degradation of $\mathrm{I} \kappa \mathrm{B} \alpha$, which eventually led to the suppression of inflammatory genes responsible for the activity of MMP-9, COX-2, and VEGF (Shishodia and Aggarwal, 2004). In another study pretreatment with guggulsterone (91) blocked the NF- $\kappa$ B activation, which consequently led to down regulation of COX-2 and matrix metalloproteinase expression. Likewise, Kim et al. (2008) reported the corresponding activity for the two novel glycosides, isoliquiritin (92) and isoliquiritigenin (93) (Figure 8) from Glycyrrhiza uralensi. Isoliquiritigenin (92) have shown more pronounced activity against NO then isoliquiritin (93) with additional $\mathrm{PGE}_{2}$ inhibitory activity. Moreover, it was also able to decrease LPS-induced expressions of iNOS and COX-2 at the protein and mRNA levels in a concentration-dependent manner. In another study sphondin (94) (Figure 8) a rare compound from Heracleum laciniatum was able to exhibit wide range of anti-inflammatory activities. It was observed that sphondin (93) was able to reduce the biosynthesis of $\mathrm{PGE}_{2}$ in a dose dependent manner via suppressing the COX-2 activity in IL- $1 \alpha$ induced RAW macrophage cells. A similar study was conducted by Zhou et al. (2008) focusing anti-inflammatory activity of 4-Methoxyhonokol (95) (Figure 8) isolated from Magnolia obovata. Results clearly suggest that 4-Methoxyhonokol (95) potentially inhibited the production and release of $\mathrm{NO}$ and $\mathrm{PGE}_{2}$ via mediating the activity gene expression of COX-2 and iNOS mRNA. In addition 4-Methoxyhonokol (95) blocked the NF$\kappa \mathrm{B}$ and MAPKs activation in LPS-stimulated RAW264.7 cells. Similar activity was reported for another lignin, schisandrin (96) (Figure 8) isolated from Schisandra chinensis. Schisandrin (96) significantly inhibited production of $\mathrm{NO}$ and $\mathrm{PGE}_{2}$ and gene expression of COX-2 and iNOS by suppressing the NF- $\kappa \mathrm{B}$, JNK, and p38 MAPK activation in RAW macrophage cell. In another phytochemical analysis carried out on Boerhaavia diffusa afforded 5 new and 4 known rotenoids. Among all the isolated compound boeravinone B (97) (Figure 8) have exhibited most significant COX1 and COX-2 activity with an $\mathrm{IC}_{50}$ value of 21.7 \pm 0.5 and $25.5 \pm 0.6 \mu \mathrm{M}$. Likewise in a similar study macrolide archazolid A (ArcA) (98) (Figure 8) from the myxobacterium Archangium gephyra was tested against LOX-5 and mPGES-1 inhibitory activity to acces its anti-inflammatory activity. The results suggested that ArcA able to significantly inhibited the gene expression of LOX-5 and mPGES-1 in LPS induced human blood with an $\mathrm{IC}_{50}$ value of $11 \mu \mathrm{M} \pm 0.2$ and $8 \mu \mathrm{M} \pm 0.2 \log$ units respectively. Similar activity was reported in the study where naturally occurring acylphloroglucinol myrtucommulone (MC) (99) (Figure 8) from Myrtus communis L. (myrtle) was tested for its anti-inflammatory activity in IL-1 $\beta$-stimulated A549 cells. The suggested that MC able to significantly inhibited the mPGES-1mediated conversion of $\mathrm{PGH}_{2}$ to $\mathrm{PGE}_{2}$ with an $\mathrm{IC}_{50}$ of $1 \mu \mathrm{M}$. However, in the same study MC failed to show any activity against COX-2 even at higher concentrations, which completely suggest that the fall in the $\mathrm{PGE}_{2}$ production observed in the current study is due to mPGES-1 gene suppression activity (Reker et al., 2014).

\section{CONCLUSION}

Numerous classes of compounds have been explored in last two decades with significant anti-inflammatory activity. Flavonoid, terpinoids, alkaloids, and stilbenoids are the major class of compounds with potent COX-2 inhibitory activity. Although majority of flavonoids show more selectivity toward COX-1 isoenzymes. However, several studies have suggested that same compounds were significantly able to inhibit the COX-2 activity in in-vivo rate models, which suggest an alternative mechanism of action of COX-2 inhibition for flavonoids including kaempferol (47), myricetinglucuronide (49), and anthocyanin (51). Alkaloids are very potent bioactive class of compounds with significant anti-inflammatory activity. Berberine (1) form Berberis sp. exhibited most significant COX-2 activity in-vitro and animal studies. Furthermore, the gene suppression activity of berberine imparts additional COX-2 suppression through inhibition of gene promoter proteins (AP-1, Mcl-1, and Akt). Hence making it the most suitable candidate for alternative therapeutic option for treating inflammation. However, few animal studies have indicated that at higher doses Berberine losses its COX-2 selectivity and may causes COX-1 associated gastric ulceration. Hence more toxicological studies need to be carried out in order to validate and standardize the therapeutic efficacy of berberine. Moreover, in the light of the above-mentioned studied capillarisin (63) and ginsenosides (65) have also shown potential to be serve as a potential therapeutic option due to their gene suppressing activity against MyD88/TIRAP, iNOS, and COX-2. More over both compounds can suppress the transcriptional activity of NF- $\kappa \mathrm{B}$, Akt, and MAPKs via blocking the LPS induced activation. Following are the list of the natural products with significant COX-2 and COX-2 mediated $\mathrm{PGE}_{2}$ inhibitory activity along with their IC $_{50}$ values, berberine (1) $2.1 \mu \mathrm{M}$, rutaecarpine (2) $0.28 \mu \mathrm{M}$, $16 \mathrm{aH}, 17$-iso-valerate-ent-kauran-19-oic acid (9) $1.1 \mu \mathrm{M}$, ent-kaur-16-en-19-oic acid (10) $1.2 \mu \mathrm{M}$, ent-pimara-8(14), 15-dien-19-oic acid (11) $1.5 \mu \mathrm{M}$, arteminolide B (12) $7.17 \mu \mathrm{M}$, fomitopinic acid A (14) $0.15 \mu \mathrm{M}$, fomitoside $\mathrm{E}$ (15) $1.01 \mu \mathrm{M}$, fomitoside F (16) $1.15 \mu \mathrm{M}$, cyclomargenyl-3-O- $\beta$-caffeoyl ester (21) $10 \mu \mathrm{M}$, curdione (24) $1.1 \mu \mathrm{M}$, koetjapic acid (27) $1.05 \mu \mathrm{M}$, 3-oxoolean-12-en-30-oic (28) $1.54 \mu \mathrm{M}$, and betulinic acid (29) $2.59 \mu \mathrm{M}, \quad 7$-angeloyl-12-acetyl-8-methoxyindol (30) $0.003 \mu \mathrm{M}$, aiphanol (32) $9.9 \mu \mathrm{M}$ and isorhapontigenin (33) $6.2 \mu \mathrm{M},(+)$-catechin (39) $3.3 \mu \mathrm{M}$, aciculatin (46), myricetinglucuronide (49) $2.4 \mu \mathrm{M}$, taiwanin C (80) $0.12 \mu \mathrm{M}$. Moreover, all the above stated compounds can be future therapeutic alternative for treating inflammation associated diseases including neurodegenerative diseases, rheumatisms, and various cancers, where excessive COX-2 activity and $\mathrm{PGE}_{2}$ production plays significant role in development and progression.

\section{AUTHOR CONTRIBUTIONS}

All authors listed have made a substantial, direct and intellectual contribution to the work, and approved it for publication.

\section{ACKNOWLEDGMENTS}

The authors would like to thank the Universiti Kebangsaan Malaysia (UKM) for the financial support under grant number GGP-2017-005 and for allowing us to use all its facilities. 


\section{REFERENCES}

Abdelouahab, N., and Heard, C. (2008). Effect of the major glycosides of Harpagophytum procumbens (Devil's Claw) on epidermal cyclooxygenase-2 (COX-2) in vitro. J. Nat. Prod. 71, 746-749. doi: 10.1021/np070204u

Aggarwal, S., Ichikawa, H., Takada, Y., Sandur, S. K., Shishodia, S., and Aggarwal, B. B. (2006). Curcumin (diferuloylmethane) down-regulates expression of cell proliferation and antiapoptotic and metastatic gene products through suppression of IкB $\alpha$ kinase and Akt activation. Mol. Pharmacol. 69, 195-206. doi: 10.1124/mol.105.017400

Ahn, K. S., Noh, E. J., Zhao, H. L., Jung, S. H., Kang, S. S., and Kim, Y. S. (2005). Inhibition of inducible nitric oxide synthase and cyclooxygenase II by Platycodon grandiflorum saponins via suppression of nuclear factor-kappaB activation in RAW 264.7 cells. Life Sci. 76, 2315-2328. doi: 10.1016/j.lfs.2004.10.042

Aid, S., Langenbach, R., and Bosetti, F. (2008). Neuroinflammatory response to lipopolysaccharide is exacerbated in mice genetically deficient in cyclooxygenase-2. J. Neuroinflammation 5:17. doi: 10.1186/1742-2094-5-17

Akaogi, J., Nozaki, T., Satoh, M., and Yamada, H. (2006). Role of PGE2 and EP receptors in the pathogenesis of rheumatoid arthritis and as a novel therapeutic strategy. Endocr. Metab. Immune Disord. Drug Targets 6, 383-394. doi: 10.2174/187153006779025711

Akiyama, H., Barger, S., Barnum, S., Bradt, B., Bauer, J., Cole, G. M., et al. (2000). Inflammation and Alzheimer's disease. Neurobiol. Aging 21, 383-421.

Al-Attas, A. A., El-Shaer, N. S., Mohamed, G. A., Ibrahim, S. R. M., and Esmat, A. (2015). Anti-inflammatory sesquiterpenes from Costus speciosus rhizomes. J. Ethnopharmacol. 176, 365-374. doi: 10.1016/j.jep.2015.11.026

An, S.-W., Kim, Y.-G., Kim, M.-H., Lee, B.-I., Lee, S.-H., Kwon, H.-I., et al. (1999). Comparison of Hepatic Detoxification activity and reducing Serum Alcohol concentration of Hovenia dulsis \$ $\mathrm{T}_{-}\{\mathrm{HUNB}\}$ \$ and Alnus japonica Steud. Korean J. Med. Crop Sci. 7, 263-268.

Aquila, S., Rojano, B., Recio, M. C., Giner, R. M., Schinella, G. R., Debenedetti, S. L., et al. (2009). Anti-inflammatory activity of berenjenol and related compounds. Planta Med. 75, 18-23. doi: 10.1055/s-0028-1088343

Armstrong, J. M., Boura, A. L., Hamberg, M., and Samuelsson, B. (1976). A comparison of the vasodepressor effects of the cyclic endoperoxides PGG2 and PGH2 with those of PGD2 and PGE2 in hypertensive and normotensive rats. Eur. J. Pharmacol. 39, 251-258. doi: 10.1016/0014-2999(76) 90133-3

Arulselvan, P., Fard, M. T., Tan, W. S., Gothai, S., Fakurazi, S., Norhaizan, M. E., et al. (2016). Role of antioxidants and natural products in inflammation. Oxid. Med. Cell. Longev. 2016:5276130. doi: 10.1155/2016/5276130

Attiq, A., Jalil, J., and Husain, K. (2017). Annonaceae: breaking the wall of inflammation. Front. Pharmacol. 8:752. doi: 10.3389/fphar.2017.00752

Avis, I., Hong, S. H., Martinez, A., Moody, T., Choi, Y. H., Trepel, J., et al. (2001). Five-lipoxygenase inhibitors can mediate apoptosis in human breast cancer cell lines through complex eicosanoid interactions. FASEB J. 15, 2007-2009. doi: 10.1096/fj.00-0866fje

Bairwa, K., Singh, I. N., Roy, S. K., Grover, J., Srivastava, A., and Jachak, S. M. (2013). Rotenoids from Boerhaavia diffusa as potential anti-inflammatory agents. J. Nat. Prod. 76, 1393-1398. doi: 10.1021/np300899w

Barton, G. M. (2008). A calculated response: control of inflammation by the innate immune system. J. Clin. Invest. 118, 413-420. doi: 10.1172/ JCI34431

Bauer, R., Pröbstle, A., Lotter, H., Wagner-Redecker, W., and Matthiesen, U. (1996). Cyclooxygenase inhibitory constituents from Houttuynia cordata. Phytomedicine 2, 305-308. doi: 10.1016/S0944-7113(96)80073-0

Bhat, K. P., and Pezzuto, J. M. (2002). Cancer chemopreventive activity of resveratrol. Ann. N. Y. Acad. Sci. 957, 210-229. doi: 10.1111/j.1749-6632.2002.tb02918.x

Bing, R. J., and Lomnicka, M. (2002). Why do cyclo-oxygenase-2 inhibitors cause cardiovascular events? J. Am. Coll. Cardiol. 39, 521-522. doi: 10.1016/S0735-1097(01)01749-1

Bjarnason, I., and Rainsford, K. (2001). Are cyclooxygenase 2 inhibitors free of gastrointestinal side effects? West. J. Med. 175:267. doi: 10.1136/ewjm.175.4.267

Blunt, J. W., Copp, B. R., Munro, M. H., Northcote, P. T., and Prinsep, M. R. (2005). Review: marine natural products. Nat. Prod. Rep. 22, 15-61. doi: $10.1039 / \mathrm{b} 415080 \mathrm{p}$
Bombardelli, E., Morazzoni, P., Cristoni, A., and Seghizzi, R. (2001) Pharmaceutical and Cosmetic formulations With Antimicrobial Activity. Google Patent.

Bora, K. S., and Sharma, A. (2011). The genus Artemisia: a comprehensive review. Pharm. Biol. 49, 101-109. doi: 10.3109/13880209.2010.497815

Breitner, J. C. (1996). Inflammatory processes and antiinflammatory drugs in Alzheimer's disease: a current appraisal. Neurobiol. Aging 17, 789-794. doi: 10.1016/0197-4580(96)00109-1

Brzozowski, T., Konturek, P. C., Konturek, S. J., Sliwowski, Z., Pajdo, R., Drozdowicz, D., et al. (2001). Classic NSAID and selective cyclooxygenase (COX)-1 and COX-2 inhibitors in healing of chronic gastric ulcers. Microsc. Res. Tech. 53, 343-353. doi: 10.1002/jemt.1102

BV, B.-C., and BE, T. (2000). Alzheimer's Disease and Inflammation.

Candelario-Jalil, E., de Oliveira, A. C. P., Gräf, S., Bhatia, H. S., Hüll, M., Muñoz, E., et al. (2007). Resveratrol potently reduces prostaglandin E 2 production and free radical formation in lipopolysaccharide-activated primary rat microglia. J. Neuroinflammation 4:25. doi: 10.1186/1742-2094-4-25

Capdevila, J. H., Falck, J. R., and Harris, R. C. (2000). Cytochrome P450 and arachidonic acid bioactivation: molecular and functional properties of the arachidonate monooxygenase. J. Lipid Res. 41, 163-181.

Chandrasekaran, C. V., Deepak, H. B., Thiyagarajan, P., Kathiresan, S., Sangli, G. K., Deepak, M., et al. (2011). Dual inhibitory effect of Glycyrrhiza glabra (GutGard) on COX and LOX products. Phytomedicine 18, 278-284. doi: 10.1016/j.phymed.2010.08.001

Chandrasekharan, N., and Simmons, D. L. (2004). The cyclooxygenases. Genome Biol. 5:241. doi: 10.1186/gb-2004-5-9-241

Chen, Y.-C., Shen, S.-C., Chen, L.-G., Lee, T. J., and Yang, L.-L. (2001b). Wogonin, baicalin, and baicalein inhibition of inducible nitric oxide synthase and cyclooxygenase- 2 gene expressions induced by nitric oxide synthase inhibitors and lipopolysaccharide. Biochem. Pharmacol. 61, 1417-1427. doi: 10.1016/S0006-2952(01)00594-9

Chen, Y. C., Shen, S. C., Lee, W. R., Hou, W. C., Yang, L. L., and Lee, T. J. (2001a). Inhibition of nitric oxide synthase inhibitors and lipopolysaccharide induced inducible NOS and cyclooxygenase- 2 gene expressions by rutin, quercetin, and quercetin pentaacetate in RAW 264.7 macrophages. J. Cell. Biochem. 82, 537-548. doi: 10.1002/jcb.1184

Chi, Y. S., Cheon, B. S., and Kim, H. P. (2001a). Effect of wogonin, a plant flavone from Scutellaria radix, on the suppression of cyclooxygenase-2 and the induction of inducible nitric oxide synthase in lipopolysaccharidetreated RAW 264.7 cells. Biochem. Pharmacol. 61, 1195-1203. doi: 10.1016/S0006-2952(01)00597-4

Chi, Y. S., Jong, H. G., Son, K. H., Chang, H. W., Kang, S. S., and Kim, H. P. (2001b). Effects of naturally occurring prenylated flavonoids on enzymes metabolizing arachidonic acid: cyclooxygenases and lipoxygenases. Biochem. Pharmacol. 62, 1185-1191. doi: 10.1016/S0006-2952(01)00773-0

Chi-Li, K., Chi, C.-W., and Liu, T.-Y. (2005). Modulation of apoptosis by berberine through inhibition of cyclooxygenase-2 and $\mathrm{Mcl}-1$ expression in oral cancer cells. In vivo $19,247-252$.

Cho, W., Nam, J. W., Kang, H. J., Windono, T., Seo, E. K., and Lee, K. T. (2009). Zedoarondiol isolated from the rhizoma of Curcuma heyneana is involved in the inhibition of iNOS, COX-2 and pro-inflammatory cytokines via the downregulation of NF- $\kappa$ B pathway in LPS-stimulated murine macrophages. Int. Immunopharmacol. 9, 1049-1057. doi: 10.1016/j.intimp.2009.04.012

Choi, D. K., Koppula, S., and Suk, K. (2011). Inhibitors of microglial neurotoxicity: focus on natural products. Molecules 16, 1021-1043. doi: 10.3390/molecules16021021

Choi, R. J., Chun, J., Khan, S., and Kim, Y. S. (2014). Desoxyrhapontigenin, a potent anti-inflammatory phytochemical, inhibits LPS-induced inflammatory responses via suppressing NF-kappaB and MAPK pathways in RAW 264.7 cells. Int. Immunopharmacol. 18, 182-190. doi: 10.1016/j.intimp.2013.11.022

Choi, R. J., Ngoc, T. M., Bae, K., Cho, H. J., Kim, D. D., Chun, J., et al. (2013). Anti-inflammatory properties of anthraquinones and their relationship with the regulation of P-glycoprotein function and expression. Eur. J. Pharm. Sci. 48, 272-281. doi: 10.1016/j.ejps.2012.10.027

Choi, R. J., Shin, E. M., Jung, H. A., Choi, J. S., and Kim, Y. S. (2011). Inhibitory effects of kaurenoic acid from Aralia continentalis on LPSinduced inflammatory response in RAW264.7 macrophages. Phytomedicine 18, 677-682. doi: 10.1016/j.phymed.2010.11.010 
Choi, Y. H., Shin, E. M., Kim, Y. S., Cai, X. F., Lee, J. J., and Kim, H. P. (2006). Antiinflammatory principles from the fruits of Evodia rutaecarpa and their cellular action mechanisms. Arch. Pharm. Res. 29, 293-297. doi: 10.1007/BF02968573

Chung, J. W., Choi, R. J., Seo, E. K., Nam, J. W., Dong, M. S., Shin, E. M., et al. (2012). Anti-inflammatory effects of (Z)-ligustilide through suppression of mitogen-activated protein kinases and nuclear factor-kappaB activation pathways. Arch. Pharm. Res. 35, 723-732. doi: 10.1007/s12272-012-0417-z

Chung, J. W., Noh, E. J., Zhao, H. L., Sim, J. S., Ha, Y. W., Shin, E. M., et al. (2008). Anti-inflammatory activity of prosapogenin methyl ester of platycodin D via nuclear factor-kappaB pathway inhibition. Biol. Pharm. Bull. 31, 2114-2120. doi: 10.1248/bpb.31.2114

Cipollone, F., Fazia, M., Iezzi, A., Zucchelli, M., Pini, B., De, D. C., et al. (2003a). Suppression of the functionally coupled cyclooxygenase-2/prostaglandin E synthase as a basis of simvastatin-dependent plaque stabilization in humans. Circulation 107, 1479-1485. doi: 10.1161/01.CIR.0000056530.03783.81

Cipollone, F., Iezzi, A., Fazia, M., Zucchelli, M., Pini, B., Cuccurullo, C., et al. (2003b). The receptor RAGE as a progression factor amplifying arachidonate-dependent inflammatory and proteolytic response in human atherosclerotic plaques: role of glycemic control. Circulation 108, 1070-1077. doi: 10.1161/01.CIR.0000086014.80477.0D

Corbit, R. M., Ferreira, J. F., Ebbs, S. D., and Murphy, L. L. (2005). Simplified extraction of ginsenosides from American ginseng (Panax quinquefolius L.) For high-performance liquid chromatography- ultraviolet analysis. J. Agric. Food Chem. 53, 9867-9873. doi: 10.1021/jf051504p

Cragg, G. M., Newman, D. J., and Snader, K. M. (1997). Natural products in drug discovery and development. J. Nat. Prod. 60, 52-60. doi: 10.1021/np9604893

Craig, W. J. (1997). Phytochemicals: guardians of our health. J. Acad. Nutr. Diet. 97, S199-S204. doi: 10.1016/S0002-8223(97)00765-7

Crofford, L. J. (1997). COX-1 and COX-2 tissue expression: implications and predictions. J. Rheumatol. Suppl. 49, 15-19.

Daniel, M. (2016). Medicinal Plants: Chemistry and Properties. CRC Press.

Dannhardt, G., Kiefer, W., Krämer, G., Maehrlein, S., Nowe, U., and Fiebich, B. (2000). The pyrrole moiety as a template for COX-1/COX-2 inhibitors. Eur. J. Med. Chem. 35, 499-510. doi: 10.1016/S0223-5234(00)00150-1

Danz, H., Stoyanova, S., Wippich, P., Brattström, A., and Hamburger, M. (2001). Identification and isolation of the cyclooxygenase-2 inhibitory principle in Isatis tinctoria. Planta Med. 67, 411-416. doi: 10.1055/s-200115805

de Crombrugghe, B., Lefebvre, V., Behringer, R. R., Bi, W., Murakami, S., and Huang, W. (2000). Transcriptional mechanisms of chondrocyte differentiation. Matrix Biol. 19, 389-394. doi: 10.1016/S0945-053X(00) 00094-9

De Montellano, P. R. O. (2005). Cytochrome P450: Structure, Mechanism, and Biochemistry. Springer Science \& Business Media. doi: 10.1007/978-1-4757-2391-5

Demeure, C. E., Yang, L. P., Desjardins, C., Raynauld, P., and Delespesse, G. (1997). Prostaglandin E2 primes naive T cells for the production of anti-inflammatory cytokines. Eur. J. Immunol. 27, 3526-3531. doi: 10.1002/eji.1830271254

Dewick, P. M. (2002). Medicinal Natural Products: A Biosynthetic Approach. John Wiley \& Sons. doi: 10.1002/9780470742761

Dieppe, P. A., Ebrahim, S., Martin, R. M., and Jüni, P. (2004). Lessons from the withdrawal of rofecoxib: patients would be safer if drug companies disclosed adverse events before licensing. BMJ 329:867. doi: 10.1136/bmj.329.7471.867

Dinchuk, J. E., Car, B. D., Focht, R. J., Johnston, J. J., Jaffee, B. D., Covington, M. B., et al. (1995). Renal abnormalities and an altered inflammatory response in mice lacking cyclooxygenase II. Nature 378:406. doi: 10.1038/378406a0

Ding, X. Z., Talamonti, M. S., Bell, R. H. Jr., and Adrian, T. E. (2005). A novel anti-pancreatic cancer agent, LY293111. Anticancer Drugs 16, 467-473. doi: 10.1097/00001813-200506000-00001

Drazen, J. M., Israel, E., and O'byrne, P. M. (1999). Treatment of asthma with drugs modifying the leukotriene pathway. N. Engl. J. Med. 340, 197-206. doi: 10.1056/NEJM199901213400306

Edelman, M. J., Watson, D., Wang, X., Morrison, C., Kratzke, R. A., Jewell, S., et al. (2008). Eicosanoid modulation in advanced lung cancer: cyclooxygenase2 expression is a positive predictive factor for celecoxib + chemotherapyCancer and Leukemia Group B Trial 30203. J. Clin. Oncol. 26, 848-855. doi: $10.1200 /$ JCO.2007.13.8081
El Halawany, A. M., Sayed, N. S. E., Abdallah, H. M., and El Dine, R. S. (2017). Protective effects of gingerol on streptozotocin-induced sporadic Alzheimer's disease: emphasis on inhibition of $\beta$-amyloid, COX-2, alpha-, beta-secretases and APH1a. Sci. Rep. 7:2902. doi: 10.1038/s41598-017-02961-0

Eliopoulos, A. G., Dumitru, C. D., Wang, C. C., Cho, J., and Tsichlis, P. N. (2002). Induction of COX-2 by LPS in macrophages is regulated by Tpl2-dependent CREB activation signals. EMBO J. 21, 4831-4840. doi: 10.1093/emboj/cdf478

Ernst, M., Grace, O. M., Saslis-Lagoudakis, C. H., Nilsson, N., Simonsen, H. T., and Rønsted, N. (2015). Global medicinal uses of Euphorbia L.(Euphorbiaceae). J. Ethnopharmacol. 176, 90-101. doi: 10.1016/j.jep.2015.10.025

Faden, A. I., Wu, J., Stoica, B. A., and Loane, D. J. (2016). Progressive inflammation-mediated neurodegeneration after traumatic brain or spinal cord injury. Br. J. Pharmacol. 173, 681-691. doi: 10.1111/bph.13179

Fang, S. C., Hsu, C. L., and Yen, G. C. (2008). Anti-inflammatory effects of phenolic compounds isolated from the fruits of Artocarpus heterophyllus. J. Agric. Food Chem. 56, 4463-4468. doi: 10.1021/jf800444g

Farah, M. H., and Samuelsson, G. (1992). Pharmacologically active phenylpropanoids from Senra incana. Planta Med. 58, 14-18. doi: 10.1055/s-2006-961380

Faulkner, D. J. (2001). Marine natural products. Nat. Prod. Rep. 18, 1R-49R. doi: 10.1039/b006897g

Fernand, V. E., Losso, J. N., Truax, R. E., Villar, E. E., Bwambok, D. K., Fakayode, S. O., et al. (2011). Rhein inhibits angiogenesis and the viability of hormone-dependent and -independent cancer cells under normoxic or hypoxic conditions in vitro. Chem. Biol. Interact. 192, 220-232. doi: 10.1016/j.cbi.2011.03.013

Fernando, I. P. S., Nah, J. W., and Jeon, Y. J. (2016). Potential anti-inflammatory natural products from marine algae. Environ. Toxicol. Pharmacol. 48, 22-30. doi: 10.1016/j.etap.2016.09.023

FitzGerald, G. A. (2004). Coxibs and cardiovascular disease. N. Engl. J. Med. 351, 1709-1711. doi: 10.1056/NEJMp048288

Fitzpatrick, F. (2004). Cyclooxygenase enzymes: regulation and function. Curr. Pharm. Des. 10, 577-588. doi: 10.2174/1381612043453144

Fortier, M., Krishnaswamy, K., Danyod, G., Boucher-Kovalik, S., and Chapdalaine, P. (2008). A postgenomic integrated view of prostaglandins in reproduction: implications for other body systems. J. Physiol. Pharmacol. 59, 65-89.

Francis, J. A., Rumbeiha, W., and Nair, M. G. (2004). Constituents in Easter lily flowers with medicinal activity. Life Sci. 76, 671-683. doi: 10.1016/j.lfs.2004.10.001

Fukuda, K., Hibiya, Y., Mutoh, M., Koshiji, M., Akao, S., and Fujiwara, H. (1999). Inhibition by berberine of cyclooxygenase-2 transcriptional activity in human colon cancer cells. J. Ethnopharmacol. 66, 227-233. doi: 10.1016/S0378-8741(98)00162-7

Fukuda, T., Song, I.-J., Ito, T., Hayakawa, H., Minamiya, Y., Kanno, A., et al. (2011). Nucleotide sequence variations in a medicinal relative of Asparagus, Asparagus cochinchinensis (Lour.) Merrill (Asparagaceae). Am. J. Plant Sci. 2:765. doi: 10.4236/ajps.2011.26091

Garavito, R. M., Malkowski, M. G., and DeWitt, D. L. (2002). The structures of prostaglandin endoperoxide $\mathrm{H}$ synthases-1 and-2. Prostaglandins Other Lipid Mediat. 68, 129-152. doi: 10.1016/S0090-6980(02)00026-6

Garcia, M., Fernandez, M., Alvarez, A., and Saenz, M. (2004). Antinociceptive and anti-inflammatory effect of the aqueous extract from leaves of Pimenta racemosa var. ozua (Mirtaceae). J. Ethnopharmacol. 91, 69-73. doi: 10.1016/j.jep.2003.11.018

Gautam, R., Karkhile, K. V., Bhutani, K. K., and Jachak, S. M. (2010). Anti-inflammatory, cyclooxygenase (COX)-2, COX-1 inhibitory, and free radical scavenging effects of Rumex nepalensis. Planta Med. 76, 1564-1569. doi: 10.1055/s-0030-1249779

Giner-Larza, E. M., Máñez, S., Recio, M. C., Giner, R. M., Prieto, J. M., CerdáNicolás, M., et al. (2001). Oleanonic acid, a 3-oxotriterpene from Pistacia, inhibits leukotriene synthesis and has anti-inflammatory activity. Eur. J. Pharmacol. 428, 137-143. doi: 10.1016/S0014-2999(01)01290-0

Glaser, K. B., and Lock, Y. W. (1995). Regulation of prostaglandin H synthase 2 expression in human monocytes by the marine natural products manoalide and scalaradial: novel effects independent of inhibition of lipid mediator production. Biochem. Pharmacol. 50, 913-922. doi: 10.1016/0006-2952(95)00211-H 
Gomez, H., Ince, C., De Backer, D., Pickkers, P., Payen, D., Hotchkiss, J., et al. (2014). A unified theory of sepsis-induced acute kidney injury: inflammation, microcirculatory dysfunction, bioenergetics and the tubular cell adaptation to injury. Shock 41:3. doi: 10.1097/SHK.0000000000000052

Gomez-Paloma, L., Monti, M. C., Terracciano, S., Casapullo, A., and Riccio, R. (2005). Chemistry and biology of anti-inflammatory marine natural products. Phospholipase A2 inhibitors. Curr. Organ. Chem. 9, 1419-1427. doi: 10.2174/1385272054880205

Grabowski, K., Baringhaus, K.cH., and Schneider, G. (2008). Scaffold diversity of natural products: inspiration for combinatorial library design. Nat. Prod. Rep. 25, 892-904. doi: 10.1039/b715668p

Grajeda-Iglesias, C., Figueroa-Espinoza, M. C., Barouh, N., Barea, B., Fernandes, A., de Freitas, V., et al. (2016). Isolation and characterization of anthocyanins from Hibiscus sabdariffa flowers. J. Nat. Prod. 79, 1709-1718. doi: 10.1021/acs.jnatprod.5b00958

Guan, F., Wang, H., Shan, Y., Chen, Y., Wang, M., Wang, Q., et al. (2014). Inhibition of COX2 and PGE2 in LPS stimulated RAW264. 7 cells by lonimacranthoide VI, a chlorogenic acid ester saponin. Biomed. Rep. 2, 760-764. doi: 10.3892/br.2014.314

Gujral, M., Sareen, K., Tangri, K., Amma, M., and Roy, A. (1960). Antiarthritic and anti-inflammatory activity of gum guggul (Balsamodendron mukul Hook). Indian J. Physiol. Pharmacol. 4:267.

Guo, L. Y., Hung, T. M., Bae, K. H., Shin, E. M., Zhou, H. Y., Hong, Y. N., et al. (2008). Anti-inflammatory effects of schisandrin isolated from the fruit of Schisandra chinensis Baill. Eur. J. Pharmacol. 591, 293-299. doi: 10.1016/j.ejphar.2008.06.074

Guruprasad, B., Chaudhary, P., Choedon, T., and Kumar, V. L. (2015). Artesunate ameliorates functional limitations in Freund's complete adjuvant-induced monoarthritis in rat by maintaining oxidative homeostasis and inhibiting COX-2 expression. Inflammation 38, 1028-1035. doi: 10.1007/s10753-014-0067-Z

Hämäläinen, M., Nieminen, R., Asmawi, M. Z., Vuorela, P., Vapaatalo, H., and Moilanen, E. (2011). Effects of flavonoids on prostaglandin E2 production and on COX-2 and mPGES-1 expressions in activated macrophages. Planta Med. 77, 1504-1511. doi: 10.1055/s-0030-1270762

Hamburger, M. (2002). Isatis tinctoria-from the rediscovery of an ancient medicinal plant towards a novel anti-inflammatory phytopharmaceutical. Phytochem. Rev. 1:333. doi: 10.1023/A:1026095608691

Han, A. R., Kim, M. S., Jeong, Y. H., Lee, S. K., and Seo, E. K. (2005). Cyclooxygenase-2 inhibitory phenylbutenoids from the rhizomes of Zingiber cassumunar. Chem. Pharm. Bull. 53, 1466-1468. doi: 10.1248/cpb.53.1466

Han, J. A., Kim, J. I., Ongusaha, P. P., Hwang, D. H., Ballou, L. R., Mahale, A., et al. (2002). p53-mediated induction of Cox-2 counteracts p53-or genotoxic stress-induced apoptosis. EMBO J. 21, 5635-5644. doi: 10.1093/emboj/cdf591

Harizi, H., Corcuff, J. B., and Gualde, N. (2008). Arachidonic-acid-derived eicosanoids: roles in biology and immunopathology. Trends Mol. Med. 14, 461-469. doi: 10.1016/j.molmed.2008.08.005

Harvey, A. L. (2008). Natural products in drug discovery. Drug Discov. Today 13, 894-901. doi: 10.1016/j.drudis.2008.07.004

Hervé, M., Angeli, V., Pinzar, E., Wintjens, R., Faveeuw, C., Narumiya, S., et al. (2003). Pivotal roles of the parasite PGD2 synthase and of the host D prostanoid receptor 1 in schistosome immune evasion. Eur. J. Immunol. 33, 2764-2772. doi: 10.1002/eji.200324143

Hiermann, A., Schramm, H., and Laufer, S. (1998). Anti-inflammatory activity of myricetin-3-O-B-D-glucuronide and related compounds. Inflamm. Res. 47, 421-427. doi: 10.1007/s000110050355

Hizaki, H., Segi, E., Sugimoto, Y., Hirose, M., Saji, T., Ushikubi, F., et al. (1999). Abortive expansion of the cumulus and impaired fertility in mice lacking the prostaglandin E receptor subtype EP2. Proc. Natl. Acad. Sci. U.S.A. 96, 10501-10506. doi: 10.1073/pnas.96.18.10501

Hofseth, L. J., and Wargovich, M. J. (2007). Inflammation, cancer, and targets of ginseng. J. Nutr. 137, 183S-185S. doi: 10.1093/jn/137.1.183S

Honda, T., Segi-Nishida, E., Miyachi, Y., and Narumiya, S. (2006). ProstacyclinIP signaling and prostaglandin E2-EP2/EP4 signaling both mediate joint inflammation in mouse collagen-induced arthritis. J. Exp. Med. 203, 325-335. doi: $10.1084 /$ jem. 20051310

Hong, C. H., Hur, S. K., Oh, O. J., Kim, S. S., Nam, K. A., and Lee, S. K. (2002). Evaluation of natural products on inhibition of inducible cyclooxygenase
(COX-2) and nitric oxide synthase (iNOS) in cultured mouse macrophage cells. J. Ethnopharmacol. 83, 153-159. doi: 10.1016/S0378-8741(02)00205-2

Hong, J., Shin, K. H., Lim, S. S., Kwak, J. H., Zee, O., Ishihara, K., et al. (2008). Lead compounds for anti-inflammatory drugs isolated from the plants of the traditional oriental medicine in Korea. Inflamm. Allergy Drug Targets 7, 195-202. doi: 10.2174/187152808785748100

Hsieh, I. N., Chang, A. S., Teng, C. M., Chen, C. C., and Yang, C. R. (2011) Aciculatin inhibits lipopolysaccharide-mediated inducible nitric oxide synthase and cyclooxygenase-2 expression via suppressing NF-kappaB and JNK/p38 MAPK activation pathways. J. Biomed. Sci. 18:28. doi: 10.1186/1423-0127-18-28 Hu, X. D., Yang, Y., Zhong, X. G., Zhang, X. H., Zhang, Y. N., Zheng, Z. P., et al. (2008). Anti-inflammatory effects of Z23 on LPS-induced inflammatory responses in RAW264.7 macrophages. J. Ethnopharmacol. 120, 447-451. doi: 10.1016/j.jep.2008.09.026

Huang, L., Fuchino, H., Kawahara, N., Narukawa, Y., Hada, N., and Kiuchi, F. (2016). Application of a new method, orthogonal projection to latent structure (OPLS) combined with principal component analysis (PCA), to screening of prostaglandin E2 production inhibitory flavonoids in Scutellaria Root. J. Nat. Med. 70, 731-739. doi: 10.1007/s11418-016-1004-2

Huang, X., and Xie, Z. (1988). Dictionary of Traditional Chinese Medicine Commercial Press.

Ichikawa, T., Li, J., Nagarkatti, P., Nagarkatti, M., Hofseth, L. J., Windust, A., et al. (2009). American ginseng preferentially suppresses STAT/iNOS signaling in activated macrophages. J. Ethnopharmacol. 125, 145-150. doi: $10.1016 /$ j.jep.2009.05.032

Imanshahidi, M., and Hosseinzadeh, H. (2008). Pharmacological and therapeutic effects of Berberis vulgaris and its active constituent, berberine. Phytother. Res. 22, 999-1012. doi: 10.1002/ptr.2399

Jackson, L., Wu, K., Mahida, Y., Jenkins, D., and Hawkey, C. J. (2000). Cyclooxygenase (COX) 1 and 2 in normal, inflamed, and ulcerated human gastric mucosa. Gut 47, 762-770. doi: 10.1136/gut.47.6.762

Jain, S. (1994). Ethnobotany and research in medicinal plants in India. Ethnobot. Search New Drugs 185, 153-168.

Jalil, J., Sabandar, C. W., Ahmat, N., Jamal, J. A., Jantan, I., Aladdin, N.A., et al. (2015). Inhibitory effect of triterpenoids from Dillenia serrata (Dilleniaceae) on prostaglandin E2 production and quantitative HPLC analysis of its koetjapic acid and betulinic acid contents. Molecules 20, 3206-3220. doi: 10.3390/molecules20023206

Jang, D. S., Cuendet, M., Hawthorne, M. E., Kardono, L. B., Kawanishi, K., Fong, H. H., et al. (2002). Prenylated flavonoids of the leaves of Macaranga conifera with inhibitory activity against cyclooxygenase-2. Phytochemistry 61, 867-872. doi: 10.1016/S0031-9422(02)00378-3

Jang, M., Cai, L., Udeani, G. O., Slowing, K. V., Thomas, C. F., Beecher, C. W., et al. (1997). Cancer chemopreventive activity of resveratrol, a natural product derived from grapes. Science 275, 218-220. doi: 10.1126/science.275.5297.218

Jaulmes, A., Thierry, S., Janvier, B., Raymondjean, M., and Maréchal, V. (2006). Activation of sPLA2-IIA and PGE2 production by high mobility group protein $\mathrm{B} 1$ in vascular smooth muscle cells sensitized by IL-1 $\beta$. FASEB J. 20, 1727-1729. doi: 10.1096/fj.05-5514fje

Jayaprakasam, B., and Nair, M. G. (2003). Cyclooxygenase-2 enzyme inhibitory withanolides from Withania somnifera leaves. Tetrahedron 59, 841-849. doi: 10.1016/S0040-4020(02)01601-0

Jayaprakasam, B., Zhang, Y., and Nair, M. G. (2004). Tumor cell proliferation and cyclooxygenase enzyme inhibitory compounds in Amaranthus tricolor. J. Agric. Food Chem. 52, 6939-6943. doi: 10.1021/jf048836z

Jin, H. Z., Lee, J. H., Lee, D., Hong, Y. S., Kim, Y. H., and Lee, J. J. (2004). Inhibitors of the LPS-induced NF- $\mathrm{B}$ activation from Artemisia sylvatica. Phytochemistry 65, 2247-2253. doi: 10.1016/j.phytochem.2004.06.034

Johnson, T. A., Sohn, J., Ward, A. E., Cohen, T. L., Lorig-Roach, N. D., Chen, H., et al. (2013). (+)-Altholactone exhibits broad spectrum immune modulating activity by inhibiting the activation of pro-inflammatory cytokines in RAW 264.7 cell lines. Bioorg. Med. Chem. 21, 4358-4364. doi: 10.1016/j.bmc.2013.04.055

Joshi, R. K. (2013). Artemisia capillaris: medicinal uses and future source for commercial uses from western himalaya of Uttrakhand. Asian J. Res. Pharm. Sci. 3, 137-140

Jung, H. J., Kim, S. G., Nam, J. H., Park, K. K., Chung, W. Y., Kim, W. B., et al. (2005). Isolation of saponins with the inhibitory effect on 
nitric oxide, prostaglandin E2 and tumor necrosis factor-alpha production from Pleurospermum kamtschaticum. Biol. Pharm. Bull. 28, 1668-1671. doi: $10.1248 / \mathrm{bpb} .28 .1668$

Jung, S.-H., Kim, S. J., Jun, B.-G., Lee, K.-T., Hong, S.-P., Oh, M. S., et al. (2013). $\alpha$-Cyperone, isolated from the rhizomes of Cyperus rotundus, inhibits LPS-induced COX-2 expression and PGE2 production through the negative regulation of NFKB signalling in RAW 264.7 cells. J. Ethnopharmacol. 147, 208-214. doi: 10.1016/j.jep.2013.02.034

Jung, W. K., Heo, S. J., Jeon, Y. J., Lee, C. M., Park, Y.-M., Byun, H.-G., et al. (2009). Inhibitory effects and molecular mechanism of dieckol isolated from marine brown alga on COX-2 and iNOS in microglial cells. J. Agric. Food Chem. 57, 4439-4446. doi: 10.1021/jf9003913

Kang, K. A., Kim, Y. W., Kim, S. U., Chae, S., Koh, Y. S., Kim, H. S., et al. (2005). G 1 phase arrest of the cell cycle by a ginseng metabolite, compound K, in U937 human monocytic leukamia cells. Arch. Pharm. Res. 28, 685-690. doi: $10.1007 / \mathrm{BF} 02969359$

Kang, T. H., Pae, H. O., Jeong, S. J., Yoo, J. C., Choi, B. M., Jun, C. D., et al. (1999). Scopoletin: an inducible nitric oxide synthesis inhibitory active constituent from Artemisia feddei. Planta Med. 65, 400-403. doi: 10.1055/s-1999-14014

Katewa, S., Chaudhary, B., and Jain, A. (2004). Folk herbal medicines from tribal area of Rajasthan, India. J. Ethnopharmacol. 92, 41-46. doi: 10.1016/j.jep.2004.01.011

Katiyar, S. K., Matsui, M. S., Elmets, C. A., and Mukhtar, H. (1999). Polyphenolic antioxidant (-)-epigallocatechin-3-gallate from green tea reduces UVBinduced inflammatory responses and infiltration of leukocytes in human skin. Photochem. Photobiol. 69, 148-153.

Kawahara, K., Hohjoh, H., Inazumi, T., Tsuchiya, S., and Sugimoto, Y. (2015). Prostaglandin E 2-induced inflammation: relevance of prostaglandin E receptors. Biochim. Biophys. Acta 1851, 414-421. doi: 10.1016/j.bbalip.2014.07.008

Kawamori, T., Kitamura, T., Watanabe, K., Uchiya, N., Maruyama, T., Narumiya, S., et al. (2005). Prostaglandin E receptor subtype EP 1 deficiency inhibits colon cancer development. Carcinogenesis 26, 353-357. doi: 10.1093/carcin/bgh322

Kelm, M. A., Nair, M. G., Strasburg, G. M., and DeWitt, D. L. (2000). Antioxidant and cyclooxygenase inhibitory phenolic compounds from Ocimum sanctum Linn. Phytomedicine 7, 7-13. doi: 10.1016/s0944-7113(00)80015-x

Khan, S., Choi, R. J., Shehzad, O., Kim, H. P., Islam, M. N., Choi, J. S., et al. (2013). Molecular mechanism of capillarisin-mediated inhibition of MyD88/TIRAP inflammatory signaling in in vitro and in vivo experimental models. J. Ethnopharmacol. 145, 626-637. doi: 10.1016/j.jep.2012.12.001

Khan, S., Shehzad, O., Jin, H. G., Woo, E. R., Kang, S. S., Baek, S. W., et al. (2012). Anti-inflammatory mechanism of 15,16-epoxy-3 $\alpha$-hydroxylabda-8,13(16),14trien-7-one via inhibition of LPS-induced multicellular signaling pathways. J. Nat. Prod. 75, 67-71. doi: 10.1021/np200666t

Khanna, D., Sethi, G., Ahn, K. S., Pandey, M. K., Kunnumakkara, A. B., Sung, B., et al. (2007). Natural products as a gold mine for arthritis treatment. Curr. Opin. Pharmacol. 7, 344-351. doi: 10.1016/j.coph.2007.03.002

Kiefer, J. R., Pawlitz, J. L., Moreland, K. T., Stegeman, R. A., Hood, W. F., Gierse, J. K., et al. (2000). Structural insights into the stereochemistry of the cyclooxygenase reaction. Nature 405:97. doi: 10.1038/35011103

Kiem, P. V., Cai, X. F., Minh, C. V., Lee, J. J., and Kim, Y. H. (2004). Kauranetype diterpene glycoside from the stem bark of Acanthopanax trifoliatus. Planta Med. 70, 282-284. doi: 10.1055/s-2004-818926

Kim, B. H., Chung, E. Y., Min, B.-K., Lee, S. H., Kim, M.-K., Min, K. R., et al. (2003). Anti-inflammatory action of legume isoflavonoid sophoricoside through inhibition on cyclooxygenase-2 activity. Planta Med. 69, 474-476. doi: 10.1055/s-2003-39712

Kim, D. W., Chi, Y. S., Son, K. H., Chang, H. W., Kim, J. S., Kang, S. S., et al. (2002). Effects of sophoraflavanone G, a prenylated flavonoid from Sophora flavescens, on cyclooxygenase-2 and in vivo inflammatory response. Arch. Pharm. Res. 25, 329-335. doi: 10.1007/BF02976635

Kim, H. J., Jang, S. I., Kim, Y. J., Chung, H. T., Yun, Y. G., Kang, T. H., et al. (2004). Scopoletin suppresses pro-inflammatory cytokines and PGE2 from LPS-stimulated cell line, RAW 264.7 cells. Fitoterapia 75, 261-266. doi: 10.1016/j.fitote.2003.12.021

Kim, H. L., Sim, J. E., Choi, H. M., Choi, I. Y., Jeong, M. Y., Park, J., et al. (2014). The AMPK pathway mediates an anti-adipogenic effect of fruits of Hovenia dulcis Thunb. Food Funct. 5, 2961-2968. doi: 10.1039/C4FO00470A
Kim, H. P., Mani, I., Iversen, L., and Ziboh, V. A. (1998). Effects of naturallyoccurring flavonoids and biflavonoids on epidermal cyclooxygenase and lipoxygenase from guinea-pigs. Prostaglandins Leukot. Essent Fatty Acids 58, 17-24. doi: 10.1016/S0952-3278(98)90125-9

Kim, J.-H., and Hahn, D.-R. (1981). Studies on the chemical constituents of Acanthopanax chiisanensis Nakai roots. Arch. Pharm. Res. 4, 59-62. doi: 10.1007/BF02856442

Kim, J.-Y., Park, S. J., Yun, K.-J., Cho, Y.-W., Park, H.-J., and Lee, K.T. (2008). Isoliquiritigenin isolated from the roots of Glycyrrhiza uralensis inhibits LPS-induced iNOS and COX-2 expression via the attenuation of NF-кB in RAW 264.7 macrophages. Eur. J. Pharmacol. 584, 175-184. doi: 10.1016/j.ejphar.2008.01.032

Kim, N.-Y., Kang, T.-H., Pae, H.-O., Choi, B.-M., Chung, H.-T., Myung, S.-W., et al. (1999). In vitro inducible nitric oxide synthesis inhibitors from Alismatis Rhizoma. Biol. Pharm. Bull. 22, 1147-1149. doi: 10.1248/bpb.22.1147

Kim, S. Y., Moon, T. C., Chang, H. W., Son, K. H., Kang, S. S., and Kim, H. P. (2002). Effects of tanshinone I isolated from Salvia miltiorrhiza bunge on arachidonic acid metabolism and in vivo inflammatory responses. Phytother. Res. 16, 616-620. doi: 10.1002/ptr.941

Kim, Y. K., Kim, R. G., Park, S. J., Ha, J. H., Choi, J. W., Park, H. J., et al. (2002). In vitro antiinflammatory activity of kalopanaxsaponin A isolated from Kalopanax pictus in murine macrophage RAW 264.7 cells. Biol. Pharm. Bull. 25, 472-476. doi: $10.1248 /$ bpb.25.472

Kim, Y. P., Lee, E. B., Kim, S. Y., Li, D., Ban, H. S., Lim, S. S., et al. (2001). Inhibition of prostaglandin E2 production by platycodin D isolated from the root of Platycodon grandiflorum. Planta Med. 67, 362-364. doi: 10.1055/s-2001-14317

Kojima, F., Kato, S., and Kawai, S. (2005). Prostaglandin E synthase in the pathophysiology of arthritis. Fundam. Clin. Pharmacol. 19, 255-261. doi: 10.1111/j.1472-8206.2005.00316.x

Kosek, E., Altawil, R., Kadetoff, D., Finn, A., Westman, M., Le Maître, E., et al. (2015). Evidence of different mediators of central inflammation in dysfunctional and inflammatory pain-interleukin-8 in fibromyalgia and interleukin-1 $\beta$ in rheumatoid arthritis. J. Neuroimmunol. 280, 49-55. doi: 10.1016/j.jneuroim.2015.02.002

Krysan, K., Reckamp, K. L., Sharma, S., and Dubinett, S. M. (2006). The potential and rationale for COX-2 inhibitors in lung cancer. Anti Cancer Agents Med. Chem. 6, 209-220. doi: 10.2174/187152006776930882

Kubo, K., Aoki, H., and Nanba, H. (1994). Anti-diabetic activity present in the fruit body of Grifola frondosa (Maitake). I. Biol. Pharm. Bull. 17, 1106-1110. doi: $10.1248 / \mathrm{bpb} .17 .1106$

Kuehl, F. A., and Egan, R. W. (1980). Prostaglandins, arachidonic acid, and inflammation. Science 210, 978-984. doi: 10.1126/science.6254151

Kuo, C. L., Chi, C. W., and Liu, T. Y. (2004). The anti-inflammatory potential of berberine in vitro and in vivo. Cancer Lett. 203, 127-137. doi: 10.1016/j.canlet.2003.09.002

Küpeli, E., Koşar, M., Yeşilada, E., and Başer, K. H. C. (2002). A comparative study on the anti-inflammatory, antinociceptive and antipyretic effects of isoquinoline alkaloids from the roots of Turkish Berberis species. Life Sci. 72, 645-657. doi: 10.1016/S0024-3205(02)02200-2

Kurumbail, R. G., Kiefer, J. R., and Marnett, L. J. (2001). Cyclooxygenase enzymes: catalysis and inhibition. Curr. Opin. Struct. Biol. 11, 752-760. doi: 10.1016/S0959-440X(01)00277-9

Lacy, E. R., and Ito, S. (1982). Microscopic analysis of ethanol damage to rat gastric mucosa after treatment with a prostaglandin. Gastroenterology 83, 619-625.

Lai, C. S., Lee, J. H., Ho, C. T., Liu, C. B., Wang, J. M., Wang, Y. J., et al. (2009). Rosmanol potently inhibits lipopolysaccharide-induced iNOS and COX-2 expression through downregulating MAPK, NF-kappaB, STAT3 and C/EBP signaling pathways. J. Agric. Food Chem. 57, 10990-10998. doi: $10.1021 /$ jf 9025713

Lajter, I., Pan, S.-P., Nikles, S., Ortmann, S., Vasas, A., Csupor-Löffler, B., et al. (2015). Inhibition of COX-2 and NF- $\mathrm{B} 1$ gene expression, NO production, 5-LOX, and COX-1 and COX-2 enzymes by extracts and constituents of Onopordum acanthium. Planta Med. 81, 1270-1276. doi: 10.1055/s-0035-1546242

Landa, P., Kokoska, L., Pribylova, M., Vanek, T., and Marsik, P. (2009). In vitro anti-inflammatory activity of carvacrol: inhibitory effect on COX-2 catalyzed prostaglandin E 2 biosynthesisb. Arch. Pharm. Res. 32, 75-78. doi: 10.1007/s12272-009-1120-6 
Langenbach, R., Loftin, C., Lee, C., and Tiano, H. (1999). Cyclooxygenase knockout mice: models for elucidating isoform-specific functions. Biochem. Pharmacol. 58, 1237-1246. doi: 10.1016/S0006-2952(99)00158-6

Langenbach, R., Morham, S. G., Tiano, H. F., Loftin, C. D., Ghanayem, B. I., Chulada, P. C., et al. (1995). Prostaglandin synthase 1 gene disruption in mice reduces arachidonic acid-induced inflammation and indomethacininduced gastric ulceration. Cell 83, 483-492. doi: 10.1016/0092-8674(95) 90126-4

Lee, D., Cuendet, M., Vigo, J. S., Graham, J. G., Cabieses, F., Fong, H. H., et al. (2001). A novel cyclooxygenase-inhibitory stilbenolignan from the seeds of Aiphanes aculeata. Org. Lett. 3, 2169-2171. doi: 10.1021/ ol015985j

Lee, J., Tae, N., Lee, J. J., Kim, T., and Lee, J. H. (2010). Eupatolide inhibits lipopolysaccharide-induced COX-2 and iNOS expression in RAW264.7 cells by inducing proteasomal degradation of TRAF6. Eur. J. Pharmacol. 636, 173-180. doi: 10.1016/j.ejphar.2010.03.021

Lee, S., Ban, H. S., Kim, Y. P., Kim, B. K., Cho, S. H., Ohuchi, K., et al. (2005). Lignans from Acanthopanax chiisanensis having an inhibitory activity on prostaglandin E2 production. Phytother. Res. 19, 103-106. doi: $10.1002 /$ ptr. 1220

Lee, S.-H., Shin, K.-H., Lee, S.-C., and Cho, S.-H. (2003). Lignans from the root of Acanthopanax chiisanensis Nakai. Korean J. Med. Crop Sci. 11, 279-283.

Lee, S. J., Lee, I. S., and Mar, W. (2003). Inhibition of inducible nitric oxide synthase and cyclooxygenase-2 activity by 1,2,3,4,6-penta-O-galloylbeta-D-glucose in murine macrophage cells. Arch. Pharm. Res. 26, 832-839. doi: $10.1007 / \mathrm{BF} 02980029$

Lev-Ari, S., Zinger, H., Kazanov, D., Yona, D., Ben-Yosef, R., Starr, A., et al. (2005). Curcumin synergistically potentiates the growth inhibitory and pro-apoptotic effects of celecoxib in pancreatic adenocarcinoma cells. Biomed. Pharmacother. 59, S276-S280. doi: 10.1016/S0753-3322(05)80045-9

Li, F., Gong, Q., Dong, H., and Shi, J. (2012). Resveratrol, a neuroprotective supplement for Alzheimer's disease. Curr. Pharm. Des. 18, 27-33. doi: $10.2174 / 138161212798919075$

Liao, Y. H., Houghton, P. J., and Hoult, J. R. (1999). Novel and known constituents from Buddleja species and their activity against leukocyte eicosanoid generation. J. Nat. Prod. 62, 1241-1245. doi: 10.1021/np990092+

Liaw, C.-C., Yang, Y.-L., Lin, C.-K., Lee, J.-C., Liao, W.-Y., Shen, C.N., et al. (2015). New meroterpenoids from Aspergillus terreus with inhibition of cyclooxygenase-2 expression. Org. Lett. 17, 2330-2333. doi: 10.1021 /acs.orglett.5b00739

Likhitwitayawuid, K., Sawasdee, K., and Kirtikara, K. (2002). Flavonoids and stilbenoids with COX-1 and COX-2 inhibitory activity from Dracaena loureiri. Planta Med. 68, 841-843. doi: 10.1055/s-2002-34403

Lim, S. J., Kim, M., Randy, A., and Nho, C. W. (2015). Inhibitory effect of the branches of Hovenia dulcis Thunb. and its constituent pinosylvin on the activities of IgE-mediated mast cells and passive cutaneous anaphylaxis in mice. Food Funct. 6, 1361-1370. doi: 10.1039/C4FO01203H

Lim, S. Y., Subedi, L., Shin, D., Kim, C. S., Lee, K. R., and Kim, S. Y. (2017). A new neolignan derivative, Balanophonin isolated from firmiana simplex delays the progress of neuronal cell death by inhibiting microglial activation. Biomol. Ther. 25:519. doi: 10.4062/biomolther.2016.224

Lin, C., Chang, C., Wang, C., Chang, M., and Yang, L. (2002). Byakangelicol, isolated from Angelica dahurica, inhibits both the activity and induction of cyclooxygenase-2 in human pulmonary epithelial cells. J. Pharm. Pharmacol. 54, 1271-1278. doi: 10.1211/002235702320402125

Lin, C. K., Tseng, C. K., Chen, K. H., Wu, S. H., Liaw, C. C., and Lee, J. C. (2015). Betulinic acid exerts anti-hepatitis $C$ virus activity via the suppression of NFkappaB- and MAPK-ERK1/2-mediated COX-2 expression. Br. J. Pharmacol. 172, 4481-4492. doi: 10.1111/bph.13233

Lucas, S. M., Rothwell, N. J., and Gibson, R. M. (2006). The role of inflammation in CNS injury and disease. Br. J. Pharmacol. 147(Suppl. 1):S232-S240. doi: 10.1038/sj.bjp.0706400

Lundin, M., Yucel-Lindberg, T., Dahllöf, G., Marcus, C., and Modeer, T. (2004). Correlation between TNFa in gingival crevicular fluid and body mass index in obese subjects. Acta Odontol. Scand. 62, 273-277. doi: $10.1080 / 00016350410000172$

Lyon, S. (2004). COXIBs on TARGET. Drug Discov. Today 9, 993. doi: $10.1016 /$ S1359-6446(04)03290-8
Ma, J., Dey, M., Yang, H., Poulev, A., Pouleva, R., Dorn, R., et al. (2007). Anti-inflammatory and immunosuppressive compounds from Tripterygium wilfordii. Phytochemistry 68, 1172-1178. doi: 10.1016/j.phytochem.2007.02.021

Mancini, J. A., Blood, K., Guay, J., Gordon, R., Claveau, D., Chan, C.-C., et al. (2001). Cloning, expression, and up-regulation of inducible rat prostaglandin E synthase during lipopolysaccharide-induced pyresis and adjuvant-induced arthritis. J. Biol. Chem. 276, 4469-4475. doi: 10.1074/jbc.M006865200

Mantyh, P. W., Clohisy, D. R., Koltzenburg, M., and Hunt, S. P. (2002). Molecular mechanisms of cancer pain. Nat. Rev. Cancer 2:201. doi: 10.1038/nrc747

Marsik, P., Kokoska, L., Landa, P., Nepovim, A., Soudek, P., and Vanek, T. (2005). In vitro inhibitory effects of thymol and quinones of Nigella sativa seeds on cyclooxygenase-1-and-2-catalyzed prostaglandin E2 biosyntheses. Planta Med. 71, 739-742. doi: 10.1055/s-2005-871288

Matsuoka, Y., Furuyashiki, T., Bito, H., Ushikubi, F., Tanaka, Y., Kobayashi, T., et al. (2003). Impaired adrenocorticotropic hormone response to bacterial endotoxin in mice deficient in prostaglandin E receptor EP1 and EP3 subtypes. Proc. Natl. Acad. Sci. U.S.A. 100, 4132-4137. doi: 10.1073/pnas.0633341100

Mattia, C., and Coluzzi, F. (2005). COX-2 inhibitors: pharmacological data and adverse effects. Minerva Anestesiol. 71, 461-470.

Mbonye, U. R., Yuan, C., Harris, C. E., Sidhu, R. S., Song, I., Arakawa, T., et al. (2008). Two distinct pathways for cyclooxygenase-2 protein degradation. $J$. Biol. Chem. 283, 8611-8623. doi: 10.1074/jbc.M710137200

McAdam, B., Mardini, I., Habib, A., Burke, A., Lawson, J., Kapoor, S., et al. (2000). Effect of regulated expression of human cyclooxygenase isoforms on eicosanoid and isoeicosanoid production in inflammation. J. Clin. Invest. 105, 1473-1482. doi: $10.1172 / J C I 9523$

Minghetti, L. (2004). Cyclooxygenase-2 (COX-2) in inflammatory and degenerative brain diseases. J. Neuropathol. Exp. Neurol. 63, 901-910. doi: 10.1093/jnen/63.9.901

Misra, S., Hascall, V. C., Markwald, R. R., O'Brien, P. E., and Ghatak, S. (2018). "Inflammation and cancer" in Wound Healing: Stem Cells Repair and Restorations, Basic and Clinical Aspects, ed K. Turksen (John Wiley \& Sons), 239-274.

Mizuno, T., and Zhuang, C. (1995). Maitake, Grifola frondosa: pharmacological effects. Food Rev. Int. 11, 135-149. doi: 10.1080/87559129509541024

Momin, R. A., De Witt, D. L., and Nair, M. G. (2003). Inhibition of cyclooxygenase (COX) enzymes by compounds from Daucus carota L. Seeds. Phytother. Res. 17, 976-979. doi: 10.1002/ptr.1296

Moon, T., Murakami, M., Kudo, I., Son, K., Kim, H., Kang, S., et al. (1999). A new class of COX-2 inhibitor, rutaecarpine from Evodia rutaecarpa. Inflamm. Res. 48, 621-625. doi: $10.1007 / \mathrm{s} 000110050512$

Morham, S. G., Langenbach, R., Loftin, C. D., Tiano, H. F., Vouloumanos, N., Jennette, J. C., et al. (1995). Prostaglandin synthase 2 gene disruption causes severe renal pathology in the mouse. Cell 83, 473-482. doi: 10.1016/0092-8674(95)90125-6

Morita, I. (2002). Distinct functions of COX-1 and COX-2. Prostaglandins Other Lipid Mediat. 68, 165-175. doi: 10.1016/S0090-6980(02)00029-1

Moriyama, T., Higashi, T., Togashi, K., Iida, T., Segi, E., Sugimoto, Y., et al. (2005). Sensitization of TRPV1 by EP 1 and IP reveals peripheral nociceptive mechanism of prostaglandins. Mol. Pain 1:3. doi: 10.1186/1744-8069-1-3

Mulabagal, V., Subbaraju, G. V., Rao, C. V., Sivaramakrishna, C., Dewitt, D. L., Holmes, D., et al. (2009). Withanolide sulfoxide from Aswagandha roots inhibits nuclear transcription factor-kappa-B, cyclooxygenase and tumor cell proliferation. Phytother. Res. 23, 987-992. doi: 10.1002/ptr.2736

Murakami, M., Nakatani, Y., Tanioka, T., and Kudo, I. (2002). Prostaglandin E synthase. Prostaglandins Other Lipid Mediat. 68, 383-399. doi: 10.1016/S0090-6980(02)00043-6

Murakami, M., Naraba, H., Tanioka, T., Semmyo, N., Nakatani, Y., Kojima, F., et al. (2000). Regulation of prostaglandin E2 biosynthesis by inducible membraneassociated prostaglandin E2 synthase that acts in concert with cyclooxygenase2. J. Biol. Chem. 275, 32783-32792. doi: 10.1074/jbc.M003505200

Murata, T., Ushikubi, F., Matsuoka, T., Hirata, M., Yamasaki, A., Sugimoto, Y., et al. (1997). Altered pain perception and inflammatory response in mice lacking prostacyclin receptor. Nature 388:678. doi: 10.1038/41780

Myers, L. K., Kang, A. H., Postlethwaite, A. E., Rosloniec, E. F., Morham, S. G., Shlopov, B. V., et al. (2000). The genetic ablation of cyclooxygenase 2 prevents the development of autoimmune arthritis. Arthritis Rheumatol. 43, 2687-2693. doi: 10.1002/1529-0131(200012)43:12<2687::AID-ANR8>3.0.CO;2-9 
Myers, N., Mittermeier, R. A., Mittermeier, C. G., da Fonseca, G. A., and Kent, J. (2000). Biodiversity hotspots for conservation priorities. Nature 403:853. doi: $10.1038 / 35002501$

Nakamura, T., Kodama, N., Arai, Y., Kumamoto, T., Higuchi, Y., Chaichantipyuth, C., et al. (2009). Inhibitory effect of oxycoumarins isolated from the Thai medicinal plant Clausena guillauminii on the inflammation mediators, iNOS, TNF- $\alpha$, and COX-2 expression in mouse macrophage RAW 264.7. J. Nat. Med. 63, 21-27. doi: 10.1007/s11418-008-0277-5

Nakatani, Y., Hokonohara, Y., Kakuta, S., Sudo, K., Iwakura, Y., and Kudo, I. (2007). Knockout mice lacking cPGES/p23, a constitutively expressed PGE 2 synthetic enzyme, are peri-natally lethal. Biochem. Biophys. Res. Commun. 362, 387-392. doi: 10.1016/j.bbrc.2007.07.180

Nathan, C. (2002). Points of control in inflammation. Nature 420:846. doi: 10.1038 /nature 01320

Noh, E. J., Ahn, K. S., Shin, E. M., Jung, S. H., and Kim, Y. S. (2006). Inhibition of lipopolysaccharide-induced iNOS and COX-2 expression by dehydroevodiamine through suppression of NF-kappaB activation in RAW 264.7 macrophages. Life Sci. 79, 695-701. doi: 10.1016/j.lfs.2006.02.020

Noreen, Y., Serrano, G., Perera, P., and Bohlin, L. (1998). Flavan-3-ols isolated from some medicinal plants inhibiting COX-1 and COX2 catalysed prostaglandin biosynthesis. Planta Med. 64, 520-524. doi: $10.1055 /$ s-2006-957506

Nutting, E., and Cammarata, P. (1969). Effects of prostaglandins on fertility in female rats. Nature 222, 287-288. doi: 10.1038/222287a0

Ogundaini, A., Farah, M., Perera, P., Samuelsson, G., and Bohlin, L. (1996). Isolation of two new antiinflammatory biflavanoids from Sarcophyte piriei. J. Nat. Prod. 59, 587-590. doi: 10.1021/np960386k

Oh, O. J., Min, H. Y., and Lee, S. K. (2007). Inhibition of inducible prostaglandin E2 production and cyclooxygenase-2 expression by curdione from Curcuma zedoaria. Arch. Pharm. Res. 30, 1236-1239. doi: 10.1007/BF02980264

Öhd, J. F., Nielsen, C. K., Campbell, J., Landberg, G., Löfberg, H., and Sjölander, A. (2003). Expression of the leukotriene D4 receptor CysLT1, COX-2, and other cell survival factors in colorectal adenocarcinomas. Gastroenterology 124, 57-70. doi: 10.1053/gast.2003.50011

Pan, C.-H., Kim, E. S., Jung, S. H., Nho, C. W., and Lee, J. K. (2008). Tectorigenin inhibits IFN- $\gamma /$ LPS-induced inflammatory responses in murine macrophage RAW 264.7 cells. Arch. Pharm. Res. 31, 1447-1456. doi: 10.1007/s12272-001-2129-7

Panda, H. (2004). Handbook on Medicinal Herbs With Uses. Asia Pacific Business Press Inc.

Park, H. J., Kim, I. T., Won, J. H., Jeong, S. H., Park, E. Y., Nam, J. H., et al. (2007). Anti-inflammatory activities of ent- $16 \alpha \mathrm{H}, 17$-hydroxy-kauran-19-oic acid isolated from the roots of Siegesbeckia pubescens are due to the inhibition of iNOS and COX-2 expression in RAW 264.7 macrophages via NF- $\kappa$ B inactivation. Eur. J. Pharmacol. 558, 185-193. doi: 10.1016/j.ejphar.2006.11.036

Park, J. Y., Pillinger, M. H., and Abramson, S. B. (2006). Prostaglandin E2 synthesis and secretion: the role of PGE2 synthases. Clin. Immunol. 119, 229-240. doi: 10.1016/j.clim.2006.01.016

Park, S., Yeo, M., Jin, J.-H., Lee, K.-M., Jung, J.-Y., Choue, R., et al. (2005). Rescue of Helicobacter pylori-induced cytotoxicity by red ginseng. Dig. Dis. Sci. 50, 1218-1227. doi: 10.1007/s10620-005-2763-x

Paruchuri, S., Mezhybovska, M., Juhas, M., and Sjölander, A. (2006). Endogenous production of leukotriene D 4 mediates autocrine survival and proliferation via CysLT 1 receptor signalling in intestinal epithelial cells. Oncogene 25:6660. doi: 10.1038/sj.onc.1209666

Patwardhan, B., Vaidya, A. D., and Chorghade, M. (2004). Ayurveda and natural products drug discovery. Curr. Sci. 86, 789-799.

Paul, A. T., Gohil, V. M., and Bhutani, K. K. (2006). Modulating TNFa signaling with natural products. Drug Discov. Today 11, 725-732. doi: 10.1016/j.drudis.2006.06.002

Perera, P., Ringbom, T., Huss, U., Vasänge, M., and Bohlin, L. (2001). “Search for natural products which affect cyclooxygenase-2," in Bioactive Compounds from Natural Sources (London: Taylor \& Francis), 433-472.

Peters, S., MacGlashan, D., Schulman, E., Schleimer, R., Hayes, E., Rokach, J., et al. (1984). Arachidonic acid metabolism in purified human lung mast cells. J. Immunol. 132, 1972-1979.

Petrovska, B. B. (2012). Historical review of medicinal plants' usage. Pharmacogn. Rev. 6, 1-15. doi: 10.4103/0973-7847.95849
Phipps, R. P., Stein, S. H., and Roper, R. L. (1991). A new view of prostaglandin $\mathrm{E}$ regulation of the immune response. Immunol. Today 12, 349-352. doi: 10.1016/0167-5699(91)90064-Z

Piomelli, D., Volterra, A., Dale, N., Siegelbaum, S., Kandel, E., Schwartz, J., et al. (1987). Lipoxygenase metabolites of arachidonic acid as second messengers for presynaptic inhibition of Aplysia sensory cells. Nature 328, 38. doi: $10.1038 / 328038 \mathrm{a} 0$

Plescia, O. J., Smith, A. H., and Grinwich, K. (1975). Subversion of immune system by tumor cells and role of prostaglandins. Proc. Natl. Acad. Sci. U.S.A. 72, 1848-1851. doi: 10.1073/pnas.72.5.1848

Pockaj, B. A., Basu, G. D., Pathangey, L. B., Gray, R. J., Hernandez, J. L., Gendler, S. J., et al. (2004). Reduced T-cell and dendritic cell function is related to cyclooxygenase-2 overexpression and prostaglandin E2 secretion in patients with breast cancer. Ann. Surg. Oncol. 11, 328-339. doi: 10.1245/ASO.2004.05.027

Polya, G. (2003). Biochemical Targets of Plant Bioactive Compounds: A Pharmacological Reference Guide to Sites of Action and Biological Effects. CRC Press. doi: 10.1021/ja033608r

Pongprayoon, U., Baeckström, P., Jacobsson, U., Lindström, M., and Bohlin, L. (1991). Compounds inhibiting prostaglandin synthesis isolated from Ipomoea pes-caprae. Planta Med. 57, 515-518. doi: 10.1055/s-2006-960196

Ponik, S. M., and Pavalko, F. M. (2004). Formation of focal adhesions on fibronectin promotes fluid shear stress induction of COX-2 and PGE2 release in MC3T3-E1 osteoblasts. J. Appl. Physiol. 97, 135-142. doi: 10.1152/japplphysiol.01260.2003

Potts, B. C., Faulkner, D. J., and Jacobs, R. S. (1992). Phospholipase A2 inhibitors from marine organisms. J. Nat. Prod. 55, 1701-1717. doi: 10.1021/np50090a001

Pouplana, R., Lozano, J., and Ruiz, J. (2002). Molecular modelling of the differential interaction between several non-steroidal anti-inflammatory drugs and human prostaglandin endoperoxide H synthase-2 (h-PGHS-2). J. Mol. Graph. Model. 20, 329-343. doi: 10.1016/S1093-3263(01)00133-4

Pradono, P., Tazawa, R., Maemondo, M., Tanaka, M., Usui, K., Saijo, Y., et al. (2002). Gene transfer of thromboxane A2 synthase and prostaglandin I2 synthase antithetically altered tumor angiogenesis and tumor growth. Cancer Res. 62, 63-66.

Prajapati, N. D., Purohit, S., Sharma, A., and Kumar, T. (2003). Medicinal Plants, 3rd Edn. Agrobios published company.

Pyee, Y., Chung, H. J., Choi, T. J., Park, H. J., Hong, J. Y., Kim, J. S., et al. (2014). Suppression of inflammatory responses by handelin, a guaianolide dimer from Chrysanthemum boreale, via downregulation of NF-kappaB signaling and pro-inflammatory cytokine production. J. Nat. Prod. 77, 917-924. doi: 10.1021/np4009877

Raja, S., Ashraf, M., Anjum, A., Javeed, A., Ijaz, T., and Attiq, A. (2016) Antibacterial activity of essential oils extracted from medicinal plants against multi-drug resistant Staphylococcus aureus. J. Anim. Plant Sci. 26, 415-423.

Ramalho, T. R., Filgueiras, L. R., Pacheco de Oliveira, M. T., Lima, A. L., Bezerra-Santos, C. R., Jancar, S., et al. (2016). Gamma-terpinene modulation of LPS-stimulated macrophages is dependent on the PGE2/IL-10 axis. Planta Med. 82, 1341-1345. doi: 10.1055/s-0042-107799

Ramírez-Cisneros, M. A., Rios, M. Y., Ríos-Gómez, R., and Aguilar-Guadarrama, A. B. (2012). Cycloartanes from Krameria pauciflora and their in vitro PLA(2), COX-1, and COX-2 enzyme inhibitory activities. Planta Med. 78, 1942-1948. doi: $10.1055 /$ s-0032-1327882

Rasool, M., and Varalakshmi, P. (2006). Immunomodulatory role of Withania somnifera root powder on experimental induced inflammation: an in vivo and in vitro study. Vascul. Pharmacol. 44, 406-410. doi: 10.1016/j.vph.2006.01.015

Rates, S. M. K. (2001). Plants as source of drugs. Toxicon 39, 603-613. doi: 10.1016/S0041-0101(00)00154-9

Ravikanth, V., Niranjan Reddy, V. L., Prabhakar Rao, T., Diwan, P. V., Ramakrishna, S., and Venkateswarlu, Y. (2002). Macrocyclic diterpenes from Euphorbia nivulia. Phytochemistry 59, 331-335. doi: 10.1016/S0031-9422(01)00461-7

Ray, A. B., and Gupta, M. (1994). "Withasteroids, a growing group of naturally occurring steroidal lactones," in Fortschritte der Chemie organischer Naturstoffe/Progress in the Chemistry of Organic Natural Products. (Springer), 1-106. doi: 10.1007/978-3-7091-9281-8_1

Ray, W. A., Stein, C. M., Daugherty, J. R., Hall, K., Arbogast, P. G., and Griffin, M. R. (2002). COX-2 selective non-steroidal anti-inflammatory 
drugs and risk of serious coronary heart disease. Lancet 360, 1071-1073. doi: 10.1016/S0140-6736(02)11131-7

Reker, D., Perna, A. M., Rodrigues, T., Schneider, P., Reutlinger, M., Mönch, B., et al. (2014). Revealing the macromolecular targets of complex natural products. Nat. Chem. 6:1072. doi: 10.1038/nchem.2095

Ricciotti, E., and FitzGerald, G. A. (2011). Prostaglandins and inflammation. Arterioscler. Thromb. Vasc. Biol. 31, 986-1000. doi: 10.1161/ATVBAHA.110.207449

Rimando, A. M., Cuendet, M., Desmarchelier, C., Mehta, R. G., Pezzuto, J. M., and Duke, S. O. (2002). Cancer chemopreventive and antioxidant activities of pterostilbene, a naturally occurring analogue of resveratrol. J. Agric. Food Chem. 50, 3453-3457. doi: 10.1021/jf0116855

Rouzer, C. A., and Marnett, L. J. (2003). Mechanism of free radical oxygenation of polyunsaturated fatty acids by cyclooxygenases. Chem. Rev. 103, 2239-2304. doi: $10.1021 /$ cr000068x

Rouzer, C. A., and Marnett, L. J. (2009). Cyclooxygenases: structural and functional insights. J. Lipid Res. 50, S29-S34. doi: 10.1194/jlr.R800042-JLR200

Rubin, P., and Mollison, K. W. (2007). Pharmacotherapy of diseases mediated by 5 -lipoxygenase pathway eicosanoids. Prostaglandins Other Lipid Mediat. 83, 188-197. doi: 10.1016/j.prostaglandins.2007.01.005

Saadawi, S., Jalil, J., Jasamai, M., and Jantan, I. (2012). Inhibitory effects of acetylmelodorinol, chrysin and polycarpol from Mitrella kentii on prostaglandin $\mathrm{E} 2$ and thromboxane $\mathrm{B} 2$ production and platelet activating factor receptor binding. Molecules 17, 4824-4835. doi: 10.3390/molecules17054824

Samad, T. A., Moore, K. A., Sapirstein, A., Billet, S., Allchorne, A., Poole, S., et al. (2001). Interleukin-1 $\beta$-mediated induction of Cox- 2 in the CNS contributes to inflammatory pain hypersensitivity. Nature 410:471. doi: 10.1038/35068566

Sampey, A. V., Monrad, S., and Crofford, L. J. (2005). Microsomal prostaglandin E synthase-1: the inducible synthase for prostaglandin E 2. Arthritis Res. Ther. 7:114. doi: $10.1186 /$ ar 1748

Samuelsson, B., Goldyne, M., Granström, E., Hamberg, M., Hammarström, S., and Malmsten, C. (1978). Prostaglandins and thromboxanes. Annu. Rev. Biochem. 47, 997-1029. doi: 10.1146/annurev.bi.47.070178.005025

Santos, C. M., Ribeiro, D., Silva, A. M., and Fernandes, E. (2017). 2, 3-Diarylxanthones as potential inhibitors of Arachidonic acid metabolic pathways. Inflammation 40, 956-964. doi: 10.1007/s10753-017-0540-6

Saraf, A. (2010). Phytochemical and antimicrobial studies of medicinal plant Costus speciosus (Koen.). J. Chem. 7, S405-S413. doi: 10.1155/2010/605735

Schneider, C., and Brash, A. R. (2000). Stereospecificity of hydrogen abstraction in the conversion of arachidonic acid to 15R-HETE by aspirintreated cyclooxygenase-2 IMPLICATIONS FOR THE ALIGNMENT OF SUBSTRATE IN THE ACTIVE SITE. J. Biol. Chem. 275, 4743-4746. doi: 10.1074/jbc.275.7.4743

Schönbeck, U., Sukhova, G. K., Graber, P., Coulter, S., and Libby, P. (1999). Augmented expression of cyclooxygenase-2 in human atherosclerotic lesions. Am. J. Pathol. 155, 1281-1291. doi: 10.1016/S0002-9440(10)65230-3

Sciulli, M. G., Capone, M. L., Tacconelli, S., and Patrignani, P. (2005). The future of traditional nonsteroidal antiinflammatory drugs and cyclooxygenase2 inhibitors in the treatment of inflammation and pain. Pharmacol. Rep. 57:66.

Seeram, N., Momin, R., Nair, M., and Bourquin, L. (2001). Cyclooxygenase inhibitory and antioxidant cyanidin glycosides in cherries and berries. Phytomedicine 8, 362-369. doi: 10.1078/0944-7113-00053

Seeram, N. P., Cichewicz, R. H., Chandra, A., and Nair, M. G. (2003). Cyclooxygenase inhibitory and antioxidant compounds from crabapple fruits. J. Agric. Food Chem. 51, 1948-1951. doi: 10.1021/jf025993u

Seeram, N. P., Schutzki, R., Chandra, A., and Nair, M. G. (2002). Characterization, quantification, and bioactivities of anthocyanins in Cornus species. J. Agric. Food Chem. 50, 2519-2523. doi: 10.1021/jf0115903

Segal, B. H., Leto, T. L., Gallin, J. I., Malech, H. L., and Holland, S. M. (2000). Genetic, biochemical, and clinical features of chronic granulomatous disease. Medicine 79, 170-200. doi: 10.1097/00005792-200005000-00004

Segura, L., Freixa, B., Ringbom, T., Vila, R., Perera, P., Adzet, T., et al. (2000). Antiinflammatory activity of dichloromethane extract of Heterotheca inuloides in vivo and in vitro. Planta Med. 66, 553-555. doi: 10.1055/s-2000-8613

Selvam, C., and Jachak, S. M. (2004). A cyclooxygenase (COX) inhibitory biflavonoid from the seeds of Semecarpus anacardium. J. Ethnopharmacol. 95, 209-212. doi: 10.1016/j.jep.2004.07.026
Sevanian, A., and Kim, E. (1985). Phospholiphase A2 dependent release of fatty acids from peroxidized membranes. J. Free Radic. Biol. Med. 1, 263-271. doi: 10.1016/0748-5514(85)90130-8

Shaari, K., Suppaiah, V., Wai, L. K., Stanslas, J., Tejo, B. A., Israf, D. A., et al. (2011). Bioassay-guided identification of an anti-inflammatory prenylated acylphloroglucinol from Melicope ptelefolia and molecular insights into its interaction with 5-lipoxygenase. Bioorg. Med. Chem. 19, 6340-6347. doi: 10.1016/j.bmc.2011.09.001

Shacter, E., and Weitzman, S. A. (2002). Chronic inflammation and cancer. Oncology 16, 217-229.

Shakibaei, M., John, T., Schulze-Tanzil, G., Lehmann, I., and Mobasheri, A. (2007). Suppression of NF- $\mathrm{kB}$ activation by curcumin leads to inhibition of expression of cyclo-oxygenase-2 and matrix metalloproteinase- 9 in human articular chondrocytes: implications for the treatment of osteoarthritis. Biochem. Pharmacol. 73, 1434-1445. doi: 10.1016/j.bcp.2007.01.005

Sharma, J. (1977). Comparison of the anti-inflammatory activity of Commiphora mukul (an indigenous drug) with those of phenylbutazone and ibuprofen in experimental arthritis induced by mycobacterial adjuvant. Arzneimittelforschung 27, 1455-1457.

Sharma, S., Stolina, M., Yang, S. C., Baratelli, F., Lin, J. F., Atianzar, K., et al. (2003). Tumor cyclooxygenase 2-dependent suppression of dendritic cell function. Clin. Cancer Res. 9, 961-968.

Shi, H., Ma, J., Mi, C., Li, J., Wang, F., Lee, J. J., et al. (2014). Amorfrutin A inhibits TNF- $\alpha$-induced NF-kappaB activation and NF-kappaB-regulated target gene products. Int. Immunopharmacol. 21, 56-62. doi: 10.1016/j.intimp.2014.04.016

Shih, R. H., Wang, C. Y., and Yang, C.-M. (2015). NF-kappaB signaling pathways in neurological inflammation: a mini review. Front. Mol. Neurosci. 8:77. doi: $10.3389 /$ fnmol.2015.00077

Shih, Y. T., Hsu, Y. Y., Chang, F. R., Wu, Y. C., and Lo, Y. C. (2010). 6-Hydroxycleroda-3,13-dien-15,16-olide protects neuronal cells from lipopolysaccharide-induced neurotoxicity through the inhibition of microgliamediated inflammation. Planta Med. 76, 120-127. doi: 10.1055/s-0029-1186005

Shin, C. Y., Lee, W. J., Lee, E. B., Choi, E. Y., and Ko, K. H. (2002). Platycodin D and D3 increase airway mucin release in vivo and in vitro in rats and hamsters. Planta Med. 68, 221-225. doi: 10.1055/s-2002-23130

Shinkai, N., Korenaga, K., Mizu, H., and Yamauchi, H. (2008). Intra-articular penetration of ketoprofen and analgesic effects after topical patch application in rats. J. Controlled Release 131, 107-112. doi: 10.1016/j.jconrel.2008. 07.012

Shishodia, S., and Aggarwal, B. B. (2004). Guggulsterone inhibits NF$\kappa B$ and $I \kappa B \alpha$ kinase activation, suppresses expression of anti-apoptotic gene products, and enhances apoptosis. J. Biol. Chem. 279, 47148-47158. doi: $10.1074 /$ jbc.M408093200

Shishodia, S., Potdar, P., Gairola, C. G., and Aggarwal, B. B. (2003). Curcumin (diferuloylmethane) down-regulates cigarette smoke-induced NF-кB activation through inhibition of I $\mathrm{B} \alpha$ kinase in human lung epithelial cells: correlation with suppression of COX-2, MMP-9 and cyclin D1. Carcinogenesis 24, 1269-1279. doi: 10.1093/carcin/bgg078

Silva, S. A., Castro, J. C. D., Silva, T. G. D., Da-cunha, E. V., BarbosaFilho, J. M., and Silva, M. S. D. (2001). Kramentosan, a new trinorlignan from the roots of Krameria tomentosa. Nat. Prod. Lett. 15, 323-329. doi: $10.1080 / 10575630108041299$

Sinal, C. J., and Gonzalez, F. J. (2002). Guggulsterone: an old approach to a new problem. Trends Endocrinol. Metab. 13, 275-276. doi: 10.1016/S1043-2760(02)00640-9

Smith, W. L., DeWitt, D. L., and Garavito, R. M. (2000). Cyclooxygenases: structural, cellular, and molecular biology. Annu. Rev. Biochem. 69, 145-182. doi: 10.1146/annurev.biochem.69.1.145

Smith, W. L., and Langenbach, R. (2001). Why there are two cyclooxygenase isozymes. J. Clin. Invest. 107, 1491-1495. doi: 10.1172/JCI13271

Soslow, R. A., Dannenberg, A. J., Rush, D., Woerner, B., Khan, K. N., Masferrer, J., et al. (2000). COX-2 is expressed in human pulmonary, colonic, and mammary tumors. Cancer 89, 2637-2645. doi: 10.1002/1097-0142(20001215)89:12<2637::AID-CNCR17>3.0.CO;2-B

Sperling, R., Braunstein, N., Melin, J., and Reicin, A. (2001). Cyclooxygenase 2 inhibitors and thrombogenicity production: comment on the article by Crofford et al. Arthritis Rheum. 44, 1229-1230. doi: 10.1002/1529-0131(200105)44:5<1229::aid-anr209>3.0.co;2-e 
Srivastava, K. D., Kattan, J. D., Zou, Z. M., Li, J. H., Zhang, L., Wallenstein, S., et al. (2005). The Chinese herbal medicine formula FAHF-2 completely blocks anaphylactic reactions in a murine model of peanut allergy. J. Allergy Clin. Immunol. 115, 171-178. doi: 10.1016/j.jaci.2004.10.003

Su, B. N., Chang, L. C., Park, E. J., Cuendet, M., Santarsiero, B. D., Mesecar, A. D., et al. (2002). Bioactive constituents of the seeds of Brucea javanica. Planta Med. 68, 730-733. doi: 10.1055/s-2002-33798

Sugimoto, Y., Inazumi, T., and Tsuchiya, S. (2015). Roles of prostaglandin receptors in female reproduction. J. Biochem. 157, 73-80. doi: $10.1093 / \mathrm{jb} / \mathrm{mvu081}$

Suh, Y. G., Kim, Y. H., Park, M. H., Choi, Y. H., Lee, H. K., Moon, J. Y., et al. (2001). Pimarane cyclooxygenase 2 (COX-2) inhibitor and its structure-activity relationship. Bioorg. Med. Chem. Lett. 11, 559-562. doi: 10.1016/S0960-894X(01)00004-X

Suksamrarn, A., Kumpun, S., Kirtikara, K., Yingyongnarongkul, B., and Suksamrarn, S. (2002). Iridoids with anti-inflammatory activity from Vitex peduncularis. Planta Med. 68, 72-73. doi: 10.1055/s-2002-20048

Surh, Y. J. (1999). Molecular mechanisms of chemopreventive effects of selected dietary and medicinal phenolic substances. Mutat. Res. 428, 305-327. doi: 10.1016/S1383-5742(99)00057-5

Takaku, K., Sonoshita, M., Sasaki, N., Uozumi, N., Doi, Y., Shimizu, T., et al. (2000). Suppression of intestinal polyposis inApc $\Delta 716$ knockout mice by an additional mutation in the cytosolic phospholipase A2Gene. J. Biol. Chem. 275, 34013-34016. doi: 10.1074/jbc.C000586200

Tamura, K., Naraba, H., Hara, T., Nakamura, K., Yoshie, M., Kogo, H., et al. (2016). A positive feedback loop between progesterone and microsomal prostaglandin E synthase-1-mediated PGE2 promotes production of both in mouse granulosa cells. Prostaglandins Other Lipid Mediat. 123, 56-62. doi: 10.1016/j.prostaglandins.2016.05.002

Thakur, R., Puri, H. S., and Husain, A. (1989). Major Medicinal Plants of India. Lucknow: Central Institute of Medicinal and Aromatic Plants.

Tiano, H. F., Loftin, C. D., Akunda, J., Lee, C. A., Spalding, J., Sessoms, A., et al. (2002). Deficiency of either cyclooxygenase (COX)-1 or COX-2 alters epidermal differentiation and reduces mouse skin tumorigenesis. Cancer Res. 62, 3395-3401.

Tilley, S. L., Coffman, T. M., and Koller, B. H. (2001). Mixed messages: modulation of inflammation and immune responses by prostaglandins and thromboxanes. J. Clin. Invest. 108, 15-23. doi: 10.1172/JCI200113416

Tucker, P. S., Scanlan, A. T., and Dalbo, V. J. (2015). Chronic kidney disease influences multiple systems: describing the relationship between oxidative stress, inflammation, kidney damage, and concomitant disease. Oxid. Med. Cell. Longev. 2015:806358. doi: 10.1155/2015/806358

Tulp, M., and Bohlin, L. (2002). Functional versus chemical diversity: is biodiversity important for drug discovery? Trends Pharmacol. Sci. 23, 225-231. doi: 10.1016/S0165-6147(02)02007-2

Ueno, N., Takegoshi, Y., Kamei, D., Kudo, I., and Murakami, M. (2005). Coupling between cyclooxygenases and terminal prostanoid synthases. Biochem. Biophys. Res. Commun. 338, 70-76. doi: 10.1016/j.bbrc.2005.08.152

Ullah, A., Ashraf, M., Javeed, A., Anjum, A. A., Attiq, A., and Ali, S. (2016). Enhancement of anti-proliferative activities of Metformin, when combined with Celecoxib, without increasing DNA damage. Environ. Toxicol. Pharmacol. 45, 227-234. doi: 10.1016/j.etap.2016.05.017

Urizar, N. L., and Moore, D. D. (2003). GUGULIPID: a natural cholesterol-lowering agent. Annu. Rev. Nutr. 23, 303-313. doi: 10.1146/annurev.nutr.23.011702.073102

Ushikubi, F., Segi, E., Sugimoto, Y., Murata, T., Matsuoka, T., Kobayashi, T., et al. (1998). Impaired febrile response in mice lacking the prostaglandin E receptor subtype EP 3. Nature 395:281. doi: 10.1038/26233

Van der Donk, W. A., Tsai, A. L., and Kulmacz, R. J. (2002). The cyclooxygenase reaction mechanism. Biochemistry 41, 15451-15458. doi: 10.1021/bi026938h

Vane, J. R. (1971). Inhibition of prostaglandin synthesis as a mechanism of action for aspirin-like drugs. Nat. New Biol. 231:232. doi: 10.1038/newbio231232a0

Volate, S. R., Davenport, D. M., Muga, S. J., and Wargovich, M. J. (2005). Modulation of aberrant crypt foci and apoptosis by dietary herbal supplements (quercetin, curcumin, silymarin, ginseng and rutin). Carcinogenesis 26, 1450-1456. doi: 10.1093/carcin/bgi089

Wallace, J. L., McKnight, W., Reuter, B. K., and Vergnolle, N. (2000). NSAID-induced gastric damage in rats: requirement for inhibition of both cyclooxygenase 1 and 2. Gastroenterology 119, 706-714 doi: 10.1053/gast.2000.16510

Wang, D., Wang, H., Shi, Q., Katkuri, S., Walhi, W., Desvergne, B., et al. (2004). Prostaglandin E 2 promotes colorectal adenoma growth via transactivation of the nuclear peroxisome proliferator-activated receptor $\delta$. Cancer Cell 6, 285-295. doi: 10.1016/j.ccr.2004.08.011

Wang, H. Q., and Smart, R. C. (1999). Overexpression of protein kinase C-alpha in the epidermis of transgenic mice results in striking alterations in phorbol esterinduced inflammation and COX-2, MIP-2 and TNF-alpha expression but not tumor promotion. J. Cell Sci. 112, 3497-3506.

Wang, J., Zhang, P., He, H., Se, X., Sun, W., Chen, B., et al. (2017). Eburicoic acid from Laetiporus sulphureus (Bull.: Fr.) Murrill attenuates inflammatory responses through inhibiting LPS-induced activation of PI3K/Akt/mTOR/NFКB pathways in RAW264. 7 cells. Naunyn Schmiedebergs. Arch. Pharmacol. 390, 845-856. doi: 10.1007/s00210-017-1382-3

Wang, L. S., and Stoner, G. D. (2008). Anthocyanins and their role in cancer prevention. Cancer Lett. 269, 281-290. doi: 10.1016/j.canlet.2008.05.020

Wang, Q. S., Yang, L., Cui, W. Y., Chen, L., and Jiang, Y. H. (2014). Anti-inflammatory and anti-nociceptive activities of methanol extract from aerial part of Phlomis younghusbandii Mukerjee. PLoS ONE 9:e89149. doi: 10.1371/journal.pone.0089149

Weggen, S., Eriksen, J. L., Das, P., Sagi, S. A., Wang, R., Pietrzik, C. U., et al. (2001). A subset of NSAIDs lower amyloidogenic A $\beta 42$ independently of cyclooxygenase activity. Nature 414:212. doi: 10.1038/35102591

Williams, T., and Peck, M. (1977). Role of prostaglandin-mediated vasodilatation in inflammation. Nature 270:530. doi: 10.1038/270530a0

Won, J. H., Kim, J. Y., Yun, K. J., Lee, J. H., Back, N. I., Chung, H. G., et al. (2006). Gigantol isolated from the whole plants of Cymbidium goeringii inhibits the LPS-induced iNOS and COX-2 expression via NF-kappaB inactivation in RAW 264.7 macrophages cells. Planta Med. 72, 1181-1187. doi: 10.1055/s-2006-947201

Wu, D., Yu, L., Nair, M., De Witt, D., and Ramsewak, R. (2002). Cyclooxygenase enzyme inhibitory compounds with antioxidant activities from Piper methysticum (kava kava) roots. Phytomedicine 9, 41-47. doi: 10.1078/0944-7113-00068

Wu, T. Y., Yang, I. H., Tsai, Y. T., Wang, J. Y., Shiurba, R., Hsieh, T. J., et al. (2012). Isodesacetyluvaricin, an Annonaceous acetogenin, specifically inhibits gene expression of cyclooxygenase-2. J. Nat. Prod. 75, 572-576. doi: $10.1021 / \mathrm{np} 200719 \mathrm{r}$

Yang, L. L., Liang, Y. C., Chang, C. W., Lee, W. S., Kuo, C. T., Wang, C. C., et al. (2002). Effects of sphondin, isolated from Heracleum laciniatum, on IL-1 $\beta$ induced cyclooxygenase- 2 expression in human pulmonary epithelial cells. Life Sci. 72, 199-213. doi: 10.1016/S0024-3205(02)02173-2

Yang, Z., Lu, W., Ma, X., and Song, D. (2012). Bioassay-guided isolation of an alkaloid with antiangiogenic and antitumor activities from the extract of Fissistigma cavaleriei root. Phytomedicine 19, 301-305. doi: 10.1016/j.phymed.2011.11.009

Ye, F., Wu, J., Dunn, T., Yi, J., Tong, X., and Zhang, D. (2004). Inhibition of cyclooxygenase- 2 activity in head and neck cancer cells by genistein. Cancer Lett. 211, 39-46. doi: 10.1016/j.canlet.2004.03.043

Yeşilada, E., and Küpeli, E. (2002). Berberis crataegina DC. root exhibits potent anti-inflammatory, analgesic and febrifuge effects in mice and rats. J. Ethnopharmacol. 79, 237-248. doi: 10.1016/S0378-8741(01) 00387-7

Yoshikawa, K., Inoue, M., Matsumoto, Y., Sakakibara, C., Miyataka, H., Matsumoto, H., et al. (2005). Lanostane triterpenoids and triterpene glycosides from the fruit body of Fomitopsis pinicola and their inhibitory activity against COX-1 and COX-2. J. Nat. Prod. 68, 69-73. doi: 10.1021/np0 $40130 \mathrm{~b}$

Yu, S., Yan, H., Zhang, L., Shan, M., Chen, P., Ding, A., et al. (2017). A review on the phytochemistry, pharmacology, and pharmacokinetics of amentoflavone, a naturally-occurring biflavonoid. Molecules 22:299. doi: 10.3390/molecules22020299

Zeilhofer, H. (2005). The glycinergic control of spinal pain processing. Cell. Mol. Life Sci. 62, 2027-2035. doi: 10.1007/s00018-005-5107-2

Zeldin, D. C. (2001). Epoxygenase pathways of arachidonic acid metabolism. J. Biol. Chem. 276, 36059-36062. doi: 10.1074/jbc.R100 030200 
Zhang, B., Hata, R., Zhu, P., Sato, K., Wen, T.-C., Yang, L., et al. (2006). Prevention of ischemic neuronal death by intravenous infusion of a ginseng saponin, ginsenoside Rb1, that upregulates Bcl-xL expression. J. Cereb. Blood Flow Metab. 26, 708-721. doi: 10.1038/sj.jcbfm.9600225

Zhang, L., An, R., Wang, J., Sun, N., Zhang, S., Hu, J., et al. (2005). Exploring novel bioactive compounds from marine microbes. Curr. Opin. Microbiol. 8, 276-281. doi: 10.1016/j.mib.2005.04.008

Zhang, Y., Dewitt, D. L., Murugesan, S., and Nair, M. G. (2005). Cyclooxygenase2 enzyme inhibitory triterpenoids from Picrorhiza kurroa seeds. Life Sci. 77, 3222-3230. doi: 10.1016/j.lfs.2005.05.051

Zhang, Y., Mills, G. L., and Nair, M. G. (2002). Cyclooxygenase inhibitory and antioxidant compounds from the mycelia of the edible mushroom Grifola frondosa. J. Agric. Food Chem. 50, 7581-7585. doi: 10.1021/jf0257648

Zhang, Y., Mills, G. L., and Nair, M. G. (2003). Cyclooxygenase inhibitory and antioxidant compounds from the fruiting body of an edible mushroom, Agrocybe aegerita. Phytomedicine 10, 386-390. doi: 10.1078/0944-711300272
Zhou, H. Y., Shin, E. M., Guo, L. Y., Youn, U. J., Bae, K., Kang, S. S., et al. (2008). Anti-inflammatory activity of 4-methoxyhonokiol is a function of the inhibition of iNOS and COX-2 expression in RAW 264.7 macrophages via NFkappaB, JNK and p38 MAPK inactivation. Eur. J. Pharmacol. 586, 340-349. doi: 10.1016/j.ejphar.2008.02.044

Conflict of Interest Statement: The authors declare that the research was conducted in the absence of any commercial or financial relationships that could be construed as a potential conflict of interest.

Copyright (c) 2018 Attiq, Jalil, Husain and Ahmad. This is an open-access article distributed under the terms of the Creative Commons Attribution License (CC BY). The use, distribution or reproduction in other forums is permitted, provided the original author(s) and the copyright owner(s) are credited and that the original publication in this journal is cited, in accordance with accepted academic practice. No use, distribution or reproduction is permitted which does not comply with these terms. 